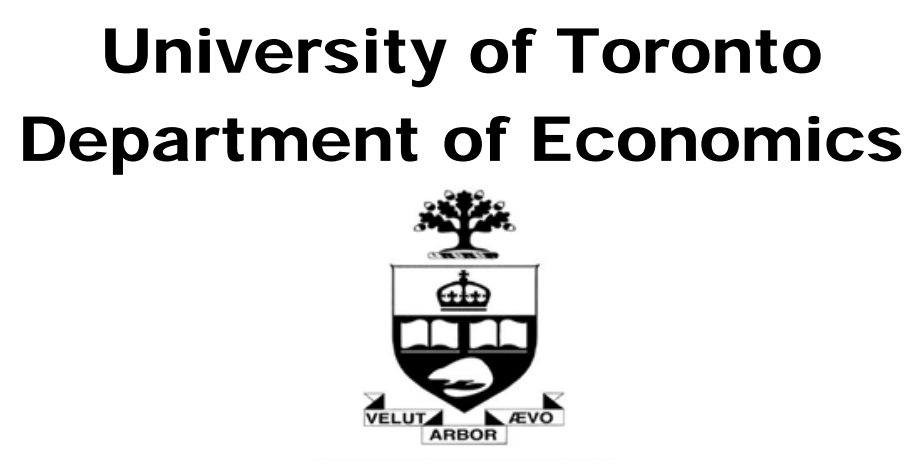

Working Paper 465

Diversification of Geographic Risk in Retail Bank Networks: Evidence from Bank Expansion after the Riegle-Neal Act

By Victor Aguirregabiria, Robert Clark and Hui Wang

October 15, 2012 


\title{
Diversification of Geographic Risk in Retail Bank Networks: Evidence from Bank Expansion after the Riegle-Neal Act
}

\author{
Victor Aguirregabiria* \\ University of Toronto
}

\author{
Robert Clark* \\ HEC Montreal
}

\author{
Hui Wang* \\ Peking University
}

This version: October 1st, 2012

\begin{abstract}
The 1994 Riegle Neal (RN) Act removed interstate banking restrictions in the US. The primary motivation was to permit geographic risk diversification (GRD). Using a factor model to measure banks' geographic risk, we show that RN expanded GRD possibilities in small states, but that few banks took advantage. Using our measure of geographic risk and a revealed preference approach, we identify preferences towards GRD separately from the contribution of other factors to branch network configuration. Risk has a negative effect on bank value, but this has been counterbalanced by economies of density/scale, reallocation/merging costs, and concerns for local market power.
\end{abstract}

Keywords: Riegle Neal Act; Commercial banking; Oligopoly competition; Branch networks; Liquidity risk; Geographic risk diversification.

JEL codes: L13, L51, G21

Victor Aguirregabiria. [Corresponding Author] Address: 150 St. George Street. Toronto, ON, M5S 3G7, Canada. Phone: (416) 978-4358. E-mail: victor.aguirregabiria@utoronto.ca

Robert Clark. Adress: 3000, chemin de la Côte-Sainte-Catherine. Montréal (Québec) H3T 2A7, Canada. Phone: (514) 340-7034. E-mail: robert.clark@hec.ca

Hui Wang. Address: Guanghua School of Management. Peking University. Beijing, 100871, China. E-mail: jackiepku@hotmail.com

\footnotetext{
${ }^{*}$ We have benefited of discussions and comments from Jason Allen, Vicente Cuñat, Christian Gourieroux, Gautam Gowrisankaran, Tom Holmes, Ali Hortacsu, Angelo Melino, Matt Mitchell, Carlos Serrano, and from seminar participants at the Bank of Canada, Bank of Spain, Duke, Toronto, Warwick, the North American meeting of the AEA in Atlanta, the SED conference in Montreal, and the second workshop on Structural Approaches to Industrial Dynamics at the Einaudi Institute.
} 


\section{Introduction}

Despite the rise of the internet, branching is still the most important tool that banks have to capture deposits. ${ }^{1}$ In order to increase its share of deposits, a bank should expand its branch network. As in other retail networks, economies of scale, economies of density, and reallocation costs play important roles in the size, spatial configuration, and evolution of branch networks. For retail banking, an additional factor that is often mentioned as important in determining the optimal configuration of branch networks is geographic risk diversification. Branches attract deposits and loans from local customers which have significant idiosyncratic risk. In a geographically non-diversified banking system, negative local shocks can have severe consequences on bank liquidity levels and may even lead to bank failures (Calomiris, 2000 p.22). By opening branches in multiple local markets with idiosyncratic risks that are not perfectly correlated, a bank can reduce the deposits and credit risks associated with its branch portfolio. Risk can be spatially correlated and so geographic risk diversification may require banks to have branches in multiple counties, or states, or possibly even multiple countries.

In this paper we study the role of diversification of geographic deposits risk in the branch location decisions of US retail banks following the passage of the Riegle Neal (RN) Act in 1994. The US banking industry is much more fragmented than elsewhere, composed of many small, locally concentrated banks. A key factor in explaining this market structure is the history of stringent restrictions on banks' ability to expand geographically, both within and across states. ${ }^{2}$ In part because the large number of failures of small community banks and thrifts during the 1970s and 1980s, there was a move towards the elimination of restrictions on geographic expansion for banks. This trend culminated in 1994 with the passage of the Riegle Neal Interstate Banking and Branching Efficiency Act, which laid the foundation for the removal of restrictions on interstate banking and branching. Permitting banks to diversify geographic risk was one of the primary motivations for enacting RN. It was believed that removing restrictions on interstate geographic expansion would be beneficial since it would allow banks to decrease the likelihood of failure by diversifying their risk over different geographic locations. As mentioned in the Economic Report of the President in 1991: "To the extent that interstate branching restrictions still prevent banks and thrifts from diversifying efficiently, they are obstacles to the efficiency, profitability, safety, and soundness of the financial sector. Accordingly, the Administration will propose legislation to allow interstate banking and branching. ${ }^{\prime \prime} 3$

\footnotetext{
${ }^{1}$ According to the 2007 annual survey of the American Bankers Association (ABA), most consumers still consider visiting physical branches to be their favorite channel for accessing banking services.

${ }^{2}$ There have been different explanations for these restrictions on expansion: from the argument that banks do not internalize the social costs of a bank failure such that, under free entry, there is excess entry relative to the social optimum (Alhadeff, 1962), to political economy interpretations (Economides et al, 1995, and Kroszner and Strahan, 1999).

${ }^{3}$ Chapter 5 of the Annual Report of the Council of Economic Advisors in the Economic Report of the President in
} 
We propose an approach to measure banks' geographic risk and use this measure to present new empirical evidence on the possibilities for geographic risk diversification available to banks, on the effects that RN had on these possibilities, and on the extent to which banks took advantage of these opportunities for diversification before and after RN. We also use our measure of risk to identify bank preferences towards geographic risk separately from other economic factors affecting the spatial configuration of branch networks such as economies of scale and density, local market power, and merging costs. Our estimates of bank preferences are based on a structural model of banks' choice of branch networks that combines modern portfolio theory with oligopoly competition.

Despite the importance of the industry and the regulatory change, there is almost no empirical evidence about these issues. There has been a number of papers studying the effect of $\mathrm{RN}$ on outcomes such as consumer welfare (Dick, 2008, and Ho and Ishii, 2010) and market valuations (Goetz, Laeven, and Levine, 2011). ${ }^{4}$ And there is a fairly large number of studies on the effect of geographic diversification on the level of risk faced by banks. From the point of view of the empirical questions that we analyze in this paper, an important limitation of these studies is the use of imprecise and generic measures of geographic diversification and risk. ${ }^{5}$ Measures of risk such as the standard deviation of net income to assets, or the standard deviation of monthly stock returns, are not limited to the risk that can be influenced by geographic diversification. As pointed out by some authors (see Hughes et al., 1996, or Carlson, 2004), these measures of risk might hide changes in geographic risk because the ability to diversify geographically may encourage banks to take riskier positions in other parts of their business so that overall the total risk they face is unchanged or even increases.

A key building block in our empirical approach is to obtain a measure of bank geographic risk that does not have the problems alluded to above since it is constructed to represent strictly the risk inherent in the different geographic locations. Our empirical analysis concentrates on banks' deposits risk. The unexpected variability over time in a bank's total volume of deposits is

1991. Similarly, Laurence Meyer, Fed Governor from 1996 to 2002, in a speech in 1996 states: "the Riegle Neal Act of 1994 essentially expands the existing regional compacts to the nation as a whole. [...] The removal of these artificial barriers to trade is beneficial and will likely improve efficiency and diversification of risks in the banking industry." (http://www.federalreserve.gov/boarddocs/speeches/1996/19961121.htm).

${ }^{4} \mathrm{~A}$ number of papers have looked at the effect of liberalization of intrastate branching restrictions on different economic outcomes such as output growth (Jayartne and Strahan, 1996), volatility (Morgan, Rime, and Strahan, 2004), or income distribution (Beck, Levine, and Levkov, 2010).

${ }^{5}$ The typical study in this literature involves regressing some measure of risk on some measure of geographic diversification. Risk is measured using some balance sheet or capital market measure such as the standard deviation of net income to assets (Liang and Rhoades 1991) or the standard deviation of monthly stock returns (Deng and Elyasian 2008). Geographic diversification is usually measured as a binary variable indicating whether or not a bank is geographically diversified (Demsetz and Strahan, 1997, Dick, 2006, Akhigbe and Whyte 2003, Schmid and Walter 2008), or the number of branches (White, 1984, Hughes et al., 1996, Carlson, 2004), or a deposit dispersion index (Deng and Elyasiani, 2008, and Liang and Rhoades, 1991). In the case of mergers, diversification is measured by how much overlap there is between the target and the acquirer's networks (Emmons, Gilbert and Yeager, 2002, Brewer, Jackson, and Jagtiani, 2000). The work of Levonian (1994) and Rose (1995) is closer to our approach. They obtain correlations in the rates of return of banks in different states to see whether there are possibilities for diversification from locating in multiple states. 
a good measure of this form of risk. Total bank deposits are the sum of the deposits over all the branches, which can be located in different local markets (i.e., counties). Although some factors influencing deposits risk are systematic and therefore common across local markets, others are not. There is an unsystematic/idiosyncratic component to deposits risk that is specific to the geographic region. The existence of this idiosyncratic component makes geographic diversification potentially beneficial. Following the standard approach in empirical finance (Ross, 1976, and Fama and French, 1992, 1993), we use a factor model to have a parsimonious specification for the variance-covariance matrix of deposits risks at each of the 3,100 US counties. We estimate this factor model using panel data on deposits at the branch level. Given our factor-model estimates, we construct measures of expected deposits and deposits risk for the branch networks of each bank during the period 19952006, as well as "efficient portfolio frontiers" for each state in 1994 (pre RN) and in 2006 (post $\mathrm{RN})$.

We find that RN has expanded substantially the possibilities of geographic diversification of deposits risk for banks with headquarters in small and homogeneous states. However, few banks have taken advantage of these new possibilities. Only a very small amount of the reduction in geographic risk during this period can be attributed to out-of-state bank expansion. In contrast, we find that most of the reduction in banks' geographic risk came from within-state bank mergers.

To explain why only a small number of banks have taken advantage of the new possibilities for geographic diversification we propose and estimate a structural model in which banks choose the location of their multiple branches, and in which they are concerned with both the expected return and the risk associated with their "portfolio" of branches. One of the purposes of estimating this model is to learn about the level of deposits risk aversion of the banks, and how this compares to the influence of other factors such as scale, density, local market power, and reallocation costs.

Using our measure of risk, data on bank mergers, and a revealed preference approach, we identify bank preferences towards geographic risk separately from the contribution of other economic factors to the spatial configuration of branch networks. Our approach is in the spirit of Jia (2008) and Holmes (2011) who have used moment inequalities methods to estimate structural models of market entry in the department store industry. For the banking industry, Akkus, Cookson, and Hortacsu (2012) use a similar approach to estimate the determinants of bank mergers. Our paper contributes also to the growing literature on empirical games of market entry in the banking industry with recent important contributions by Ackerberg and Gowrisankaran (2006), Cohen and Mazzeo (2007 and 2010), Ho and Ishii (2010), and Gowrisankaran and Krainer (2011). Our paper incorporates geographic risk diversification as a relevant determinant for the geographic structure of a retail network, and identifies this determinant separately from other factors such as economies of density, scale, and local market power.

Our results help to explain the rash of bank failures that have occurred since the beginning of 
the financial crisis. Many of the failures were single-state or single-county banks that were overly exposed to local risk without being geographically diversified. Our estimation results point out reasons why banks may not have taken advantage of the opportunities for diversification afforded them by RN.

Section 2 describes our model. Section 3 presents the data and descriptive evidence on the evolution of the US banking industry. Section 4 obtains our measure of geographic risk, and presents empirical evidence on the possibilities for diversification and the extent to which banks take advantage of them before and after Riegle Neal. Section 5 presents our estimation of bank preferences. Section 6 summarizes and concludes.

\section{Model}

This section presents a model of competition between branch networks where banks are concerned with geographic risk. ${ }^{6}$ This model provides a framework for the construction of our measures of geographic deposits risk, for the interpretation of empirical evidence on banks diversification of this risk, and for our structural estimation of the value of bank networks.

A commercial bank is a firm that accepts deposits, makes loans, and provides payment services. Banks operate using branches that compete in local markets. ${ }^{7}$ We assume that the US banking industry at some period $t$ is configured by $I_{t}$ banks and $M$ geographic local markets (e.g., counties). We index banks by $i$, markets by $m$, and time by $t$. There are two levels of competition between retail banks in our model: the local market level, and the national level. At the level of a local market, banks compete with each other for deposits and loans using their quantity choices as strategic variables (Cournot competition). The equilibrium in this game determines the amount of deposits and loans each active bank has at the local market level. At the national level, each bank chooses its branch network, i.e., the number of branches at each geographic local market. The branch network of bank $i$ can be described as a vector $\boldsymbol{n}_{i t} \equiv\left\{n_{\text {imt }}: m=1,2, \ldots, M\right\}$, where $n_{\text {imt }}$ is the number of branches that bank $i$ has in market $m$ at period $t$. The equilibrium in this game of network competition determines the number of branches that every bank has at each of the $M$ geographic markets. Liquidity from deposits can be transferred between branches of the same bank at a very low cost. A bank's liquidity is measured by the difference between its total deposits and total loans. A bank can obtain additional liquidity in the interbank money market, but this is costly.

\footnotetext{
${ }^{6}$ See Corbae and D'Erasmo (2011) for a model of bank competition that also accounts for oligopoly competition at two different geographic levels, local/regional and national. They include this model of bank competition in a general equilibrium framework and use it to study the effects of different regulations on bank failure.

${ }^{7}$ Two branches compete with each other only if they are in the same local market. The existence of transportation costs imply that consumers are willing to patronize a branch only if it is not too far away from where they live. Wang (2009) and Ho and Ishii (2010) estimate spatial models of consumer demand for retail banks. They find evidence of significant consumer disutility associated with distance traveled.
} 


\subsection{Bank competition in a local market}

Households and businesses in a local market demand loans from and supply deposits to local bank branches. Branches in the same local market are symmetrically differentiated in demand. The local demand for loans and the local supply of deposits in market $m$ at period $t$ are described by the equations $r_{m t}^{(L)}=\alpha_{m t}^{(L)}-\beta^{(L)} L_{m t}$, and $r_{m t}^{(D)}=\alpha_{m t}^{(D)}+\beta^{(D)} D_{m t}$, respectively, where: $r_{m t}^{(L)}$ and $r_{m t}^{(D)}$ represent the interest rate of loans and deposits; $L_{m t}$ and $D_{m t}$ are the total amounts of loans and deposits for all the branches in the local market; $\alpha_{m t}^{(L)}$ and $\alpha_{m t}^{(D)}$ are exogenous variables that determine the level of demand for loans and supply of deposits; and $\beta^{(L)}$ and $\beta^{(D)}$ are parameters.

The number of branches of each bank in market $m$ at period $t$ is determined in the game of network competition that we describe in section 2.2, and it is exogenous in this game of local market competition. The local manager of bank $i$ in market $m$ chooses his own amount of deposits $\left(d_{i m t}\right)$ and loans $\left(\ell_{i m t}\right)$, and his net loans to the headquarters of the bank $\left(b_{i m t}\right)$ to maximize the bank profits in this local market, subject to the constraint that $b_{i m t}=d_{i m t}-\ell_{i m t}$, where $b_{i m t}$ can be either positive or negative. From the point of view of a local manager, the demand/supply of loans from the headquarters of the bank is perfectly elastic at the interest rate $r_{t}^{(B)}$. The variable cost of managing loans and deposits at the local market is $n_{i m t}\left(c_{m t}^{(L)}\left(\ell_{i m t} / n_{i m t}\right)+c_{m t}^{(D)}\left(d_{i m t} / n_{i m t}\right)\right)$, where $c_{m t}^{(L)}($.$) and c_{m t}^{(D)}($.$) are functions that represent the cost of managing loans and deposits, respectively,$ at the branch level. These cost functions are strictly convex (i.e., increasing marginal cost), and this implies that banks with more branches in a local market have lower marginal costs and more deposits and loans in equilibrium. The variable profit of bank $i$ in local market $m$ is:

$$
\begin{aligned}
\pi_{i m t} & =r_{m t}^{(L)} \ell_{i m t}-r_{m t}^{(D)} d_{i m t}-n_{i m t}\left(c_{m t}^{(L)}\left(\frac{\ell_{i m t}}{n_{i m t}}\right)+c_{m t}^{(D)}\left(\frac{d_{i m t}}{n_{i m t}}\right)\right)+r_{t}^{(B)} b_{i m t} \\
& =\left(r_{m t}^{(L)}-r_{t}^{(B)}\right) \ell_{i m t}-\left(r_{m t}^{(D)}-r_{t}^{(B)}\right) d_{i m t}-n_{i m t}\left(c_{m t}^{(L)}\left(\frac{\ell_{i m t}}{n_{i m t}}\right)+c_{m t}^{(D)}\left(\frac{d_{i m t}}{n_{i m t}}\right)\right) .
\end{aligned}
$$

Local managers compete a la Nash-Cournot for loans and deposits. In the equilibrium of this game, a bank's deposits, loans, and profits depend on its own number of branches, the number of branches of other banks, and on the exogenous variables affecting demand for loans, supply of deposits, and variable costs in the local market. Ceteris paribus, a bank's profit increases with the number of its own branches, and decreases with the number of competing banks, and with the branches of the competitors.

For our empirical analysis, we consider a quadratic specification of variable costs: i.e., $c_{m t}^{(L)}(x)=$ $\gamma_{1 m t}^{(L)} x+\gamma_{2}^{(L)} x^{2}$, and $c_{m t}^{(D)}(x)=\gamma_{1 m t}^{(D)} x+\gamma_{2}^{(D)} x^{2}$, where $\gamma_{1 m t}^{(L)}$ and $\gamma_{1 m t}^{(D)}$ are exogenous cost shifters, and $\gamma_{2}^{(L)}$ and $\gamma_{2}^{(D)}$ are parameters. It is simple to show that in equilibrium: (a) the variable profit of a bank is equal to the sum of profits from deposits and profits from loans, $\pi_{i m t}^{*(D)}+\pi_{i m t}^{*(L)}$; (b) profits from deposits (loans) are proportional to the square of the equilibrium amount of deposits (loans) of the bank, $\pi_{i m t}^{*(D)}=\beta^{(D)}\left(1+\left[\gamma_{2}^{(D)} / \beta^{(D)} n_{i m t}\right]\right)\left(d_{i m t}^{*}\right)^{2}$, and $\pi_{i m t}^{*(L)}=\beta^{(L)}\left(1+\left[\gamma_{2}^{(L)} / \beta^{(L)}\right.\right.$ 
$n_{i m t}$ ) $\left(\ell_{i m t}^{*}\right)^{2}$; and (c) the equilibrium amount of deposits (loans) of the bank is proportional to average deposits (loans) per-branch in the market, $d_{i m t}^{*}=w_{i}^{(D)}\left(\mathbf{n}_{m t}\right) \bar{d}_{m t}$, and $\ell_{i m t}^{*}=w_{i}^{(L)}\left(\mathbf{n}_{m t}\right)$ $\bar{\ell}_{m t}$, where $\bar{d}_{m t}\left(\bar{\ell}_{m t}\right)$ is the average amount of deposits (loans) per-branch in the market. Functions $w_{i}^{(D)}\left(\mathbf{n}_{m t}\right)$ and $w_{i}^{(L)}\left(\mathbf{n}_{m t}\right)$ have the following expression, for $h=L, D$ :

$$
w_{i}^{(h)}\left(\mathbf{n}_{m t}\right) \equiv\left(\sum_{j=1}^{I_{t}} n_{j m t}\right) \frac{n_{i} /\left[n_{i}+\frac{2 \gamma_{2}^{(h)}}{\beta^{(h)}}\right]}{\sum_{j=1}^{I_{t}} n_{j} /\left[n_{j}+\frac{2 \gamma_{2}^{(h)}}{\beta^{(h)}}\right]} .
$$

The value of the parameter $\gamma_{2}^{(h)} / \beta^{(h)}$ determines the shape of this weighting factor as a function of the number of branches. When this parameter is zero, the factor $w_{i}^{(h)}\left(\mathbf{n}_{m t}\right)$ is the same for every bank active in the market, regardless of its number of branches, and equal to the average number of branches per bank. When the parameter is strictly positive, the factor increases with the number of own branches and decreases with the number of competitor branches.

\subsection{Branch networks and geographic risk}

Every period $t$, each bank chooses its branch network $\mathbf{n}_{i t}$ to maximize its expected value. Let $D_{i t} \equiv \sum_{m=1}^{M} d_{i m t}^{*}$ be the total volume of deposits of bank $i$, and let $L_{i t} \equiv \sum_{m=1}^{M} \ell_{i m t}^{*}$ be its total volume of loans. The balance sheet of a bank implies that the value of assets is equal to the value of liabilities, i.e., $L_{i t}=D_{i t}+E_{i}+B_{i t}$, where $B_{i t}$ represents the bank's net debt in the interbank market, and $E_{i}$ is bank's equity that is exogenous in our model. The value of a bank, or branch network, has the following four components:

$$
V_{i t}=\sum_{m=1}^{M} \pi_{i m t}^{*}-F C_{i t}\left(\mathbf{n}_{i t}\right)-A C_{i t}\left(\mathbf{n}_{i t}, \mathbf{n}_{i t-1}\right)-\rho_{i t} 1\left\{\frac{D_{i t}+E_{i}}{D_{i t}+E_{i}+B_{i t}} \leq \tau\right\}
$$

The first term, $\sum_{m=1}^{M} \pi_{i m t}^{*}$, is the sum of variable profits from all the local markets where the bank is active. The second term, $F C_{i t}\left(\mathbf{n}_{i t}\right)$, consists of the fixed cost of operating the branch network. This cost depends on the size and the structure of the network, e.g., (dis)economies of scale, economies of density. The third component, $A C_{i t}\left(\mathbf{n}_{i t}, \mathbf{n}_{i t-1}\right)$, includes costs of adjusting or changing the branch network, including merging costs and costs of denovo branching. Finally, the fourth term in a bank's profit is the cost of insolvency, where $\rho_{i t}$ is an exogenous variable that represents the monetary cost of insolvency, $1\{$.$\} is the indicator function, and the expression \left(D_{i t}+E_{i}\right) /\left(D_{i t}+E_{i}+B_{i t}\right) \leq \tau$ represents the condition for being insolvent. A bank is considered insolvent if its solvency ratio is lower than a certain critical value $\tau$. The solvency ratio that we consider here is the proportion of "low cost" liabilities (i.e., deposits and equity) over total liabilities.

When a bank chooses its branch network at period $t$, it has uncertainty about some of the exogenous variables that determine deposits and loans in local markets. Let $\mathbf{X}_{t}$ be a vector of variables with all the information available to banks at period $t$. A bank chooses its branch network 
$\mathbf{n}_{i t}$ to maximize its expected profit $\mathbb{E}\left(V_{i t} \mid \mathbf{X}_{t}\right)$. Our specification of the cost functions $F C_{i t}($.$) and$ $A C_{i t}(.,$.$) is described in section 5$. The rest of this section describes how we incorporate geographic risk in the model.

We abstract from strategic uncertainty/risk and assume that the game for the choice of branch network is one of complete information, such that banks' strategies are common knowledge, and every bank knows the other banks' networks choices when it decides its own network. Second, we assume that, from the point of view of geographic diversification and choice of branch network, the amount of geographic risk in a bank's equity, $E_{i}$, and in its aggregate volume of loans, $L_{i t}$, is negligible. The main source of geographic risk comes from volatility in the total volume of deposits, $D_{i t}$. We expect branch location to be substantially more important for deposits risk than for loans risk. Branch deposits are, by far, the most important source of liquidity for any commercial bank. The interbank market is the other source, but obtaining liquidity in the interbank market is more costly than from own branches. In contrast, a bank does not need to have a branch in a local market to provide loans in that market. In fact, it is becoming quite common to find households who have their mortgage with a branch located thousands of miles away from where they live, while this is still very rare for deposits accounts. ${ }^{8}$ Furthermore, during our sample period (1995 to 2006) many banks securitized their loans, especially their mortgages. Securitization reduces a bank's concern for the geographic risk of loans. Therefore, we study the relationship between the geographic configuration of a branch network and the bank's risk from deposits.

Given the local market equilibrium described above, a bank's total deposits are $D_{i t}=\sum_{m=1}^{M}$ $w_{i}\left(\mathbf{n}_{m t}\right) \bar{d}_{m t}$, and the total variable profits from deposits are equal to $\sum_{m=1}^{M} \delta_{i}\left(\mathbf{n}_{m t}\right)\left(\bar{d}_{m t}^{2}\right)$, where $\delta_{i}\left(\mathbf{n}_{m t}\right) \equiv \beta^{(D)}\left(1+\left[\gamma_{2}^{(D)} / \beta^{(D)} n_{i m t}\right]\right)\left(w_{i}\left(\mathbf{n}_{m t}\right)\right)^{2}$, and for notational simplicity we omit the superindex $(D)$ from $w_{i}^{(D)}$. We can represent the probability of insolvency as $\operatorname{Pr}\left(D_{i t} \leq \widetilde{\tau}_{i} \mid \mathbf{X}_{t}\right)$, where $\widetilde{\tau}_{i} \equiv \tau L_{i}-E_{i}$. Suppose that the stochastic process of $D_{i t}$ conditional on $\mathbf{X}_{t}$ is normally distributed, such that the probability of insolvency is equal to $\Phi\left(\left[\widetilde{\tau}_{i}-\mathbb{E}\left(D_{i t} \mid \mathbf{X}_{t}\right)\right] / \sqrt{\mathbb{V}\left(D_{i t} \mid \mathbf{X}_{t}\right)}\right)$, where $\Phi($.$) is$ the CDF of the standard normal. Therefore, the expected value of a bank can be represented as: ${ }^{9}$

$$
\begin{aligned}
\mathbb{E}\left(V_{i t} \mid \mathbf{X}_{t}\right) & =\sum_{m=1}^{M} \delta_{i}\left(\mathbf{n}_{m t}\right) \mathbb{E}\left(\bar{d}_{m t}^{2} \mid \mathbf{X}_{t}\right)-F C_{i t}\left(\mathbf{n}_{i t}\right)-A C_{i t}\left(\mathbf{n}_{i t}, \mathbf{n}_{i t-1}\right) \\
& -\rho_{i t} \Phi\left(\frac{\widetilde{\tau}_{i}-\sum_{m=1}^{M} w_{i}\left(\mathbf{n}_{m t}\right) \mathbb{E}\left(\bar{d}_{m t} \mid \mathbf{X}_{t}\right)}{\sqrt{\sum_{m=1}^{M} \sum_{m^{\prime}=1}^{M} w_{i}\left(\mathbf{n}_{m t}\right) w_{i}\left(\mathbf{n}_{m^{\prime} t}\right) \operatorname{Cov}\left(\bar{d}_{m t}, \bar{d}_{m^{\prime} t} \mid \mathbf{X}_{t}\right)}}\right)
\end{aligned}
$$

This expression shows that the value of a branch network depends on the expected value of

\footnotetext{
${ }^{8}$ For empirical evidence on this issue, see Brevoort and Wolken (2009) and table 3.2 in that paper.

${ }^{9}$ Note that the term $\mathbb{E}\left(\bar{d}_{m t}^{2} \mid \mathbf{X}_{t}\right)$ in the expected variable profit introduces a risk-loving aspect into the value of a branch network, i.e., the expected variable profits in a local market increases with the variance/risk of deposits in this market. This risk-loving element is counterbalanced by the contribution of the cost insolvency to the value of a bank.
} 
deposits per-branch at the different local markets $\left\{\mathbb{E}\left(\bar{d}_{m t} \mid \mathbf{X}_{t}\right)\right\}$, but also on the variances of deposits per-branch in these markets, $\left\{\mathbb{V}\left(\bar{d}_{m t} \mid \mathbf{X}_{t}\right)\right\}$, and on the covariances across local markets, $\operatorname{Cov}\left(\bar{d}_{m t}, \bar{d}_{m^{\prime} t} \mid \mathbf{X}_{t}\right)$.

\subsection{Factor model}

To measure deposits risk, and to study empirically the relationship of this risk with a bank's branch network, we need to estimate the expected value of deposits per-branch at each local market and their variances and covariances across markets. Since the seminal studies of Ross (1976) and Fama and French $(1992,1993)$, factor models have been commonly used in empirical finance to estimate the variance-covariance of risky assets. The key feature of a factor structure model is that the variance-covariance matrix of the $M$ asset returns can be described by a simpler, lower dimensional structure. We postulate the following model for the logarithm of deposits per branch in county $m$ at year $t$,

$$
\ln \left(\bar{d}_{m t}\right)=\alpha_{m}\left(\mathbf{X}_{t}\right)+\beta_{m}\left(\mathbf{X}_{t}\right) \mathbf{f}_{t}+u_{m t},
$$

where $\alpha_{m}($.$) is a deterministic function of \mathbf{X}_{t}$, and $\beta_{m}($.$) is a 1 \times F$ vector of deterministic functions of $\mathbf{X}_{t} . \mathbf{f}_{t}$ is an $F \times 1$ vector of random variables or factors that are common to all the markets. $u_{m t}$ is a random variable that is market specific. The random variables in $\mathbf{f}_{t}$ and $u_{m t}$ have mean zero, are mean independent of $\mathbf{X}_{t}$, and are unknown to banks when they make their investment decisions at period $t$. The scalar $\alpha_{m}\left(\mathbf{X}_{t}\right)$ is the expected value of $\ln \left(\bar{d}_{m t}\right)$ conditional on $\mathbf{X}_{t}$. The terms $\beta_{m}\left(\mathbf{X}_{t}\right) \mathbf{f}_{t}$ and $u_{m t}$ are the unexpected or risk components. The vector of factors $\mathbf{f}_{t}$ represents the systematic risk that affects every geographic market. These $F$ factors are i.i.d. over time, without loss of generality they have zero mean, and the $F \times F$ variance-covariance matrix is $\boldsymbol{\Sigma}_{\mathbf{f}}$. The effect of these systematic risk factors may vary across markets. The effect in market $m$ and period $t$ is $\beta_{m}\left(\mathbf{X}_{t}\right) \mathbf{f}_{t}$, where $\beta_{m}\left(\mathbf{X}_{t}\right)$ is the vector of factor loadings. The scalar random variable $u_{m t}$ represents the market-specific idiosyncratic risk.

The specification of the conditional mean is $\alpha_{m}\left(\mathbf{X}_{t}\right)=\alpha_{m}^{(0)}+\mathbf{X}_{m t} \boldsymbol{\alpha}^{(1)}$, where $\mathbf{X}_{m t} \subset \mathbf{X}_{t}$ is a $1 \times K$ vector of observable variables, $\alpha_{m}^{(0)}$ is a county-fixed-effect, and $\boldsymbol{\alpha}^{(1)}$ is a vector of parameters. The vector $\mathbf{X}_{m t}$ includes many observable variables at the local market level such as lagged values of the dependent variable, population, average income, or industry shares in total employment in the market. Factor loadings depend on the observable variables $\mathbf{X}_{m t}$ according to the linear system $\beta_{m}\left(\mathbf{X}_{t}\right)=\mathbf{X}_{m t} \mathbf{B}$, where $\mathbf{B}$ is a $K \times F$ matrix.

A potentially important constraint for banks' geographic risk diversification is the existence of strong spatial correlation in the supply of deposits of neighboring counties. This spatial correlation may not be fully captured by the factors $\beta_{m}\left(\mathbf{X}_{t}\right) \mathbf{f}_{t}$. Therefore, we allow the unobserved idiosyncratic shocks to be spatially correlated. For any county $m$, we define $S$ rings or concentric bands around the county. The first band is defined as the set of counties with centers that are less than 50 
miles away from the center of county $m$, excluding the own county $m$. The second band is the set of counties with centers between 50 and 100 miles away from the center of county $m$. The third band is the set of counties with centers between 100 and 200 miles away from the center of county $m$. And so on. The spatial autoregressive process of $u_{m t}$ can be represented using expression $u_{m t}=\rho_{1}$ $\tilde{u}_{m t}^{(1)}+\rho_{2} \tilde{u}_{m t}^{(2)}+\ldots+\rho_{S} \tilde{u}_{m t}^{(S)}+e_{m t}$, where $\tilde{u}_{m t}^{(s)}$ is the mean value of the shock $u$ in band $s$ around county $m, \rho_{1}, \rho_{2}, \ldots, \rho_{S}$ are parameters, and $e_{m t}$ is a residual shock that is not spatially correlated. We can write this spatial autoregressive process in matrix form as:

$$
\mathbf{u}_{t}=\rho_{1}\left[\mathbf{W}_{1} \mathbf{u}_{t}\right]+\rho_{2}\left[\mathbf{W}_{2} \mathbf{u}_{t}\right]+\ldots+\rho_{S}\left[\mathbf{W}_{S} \mathbf{u}_{t}\right]+\mathbf{e}_{t}
$$

where $\mathbf{u}_{t}$ is the $M \times 1$ vector $\left(u_{1 t}, u_{2 t}, \ldots, u_{M t}\right)^{\prime} ;$ similarly, $\mathbf{e}_{t}$ is the vector $\left(e_{1 t}, e_{2 t}, \ldots, e_{M t}\right)^{\prime}$; and $\mathbf{W}^{\prime} s$ are $M \times M$ weighting matrices such that the $m$-th row of matrix $\mathbf{W}_{s}$ contains the $0 s$ for county $m$ and for counties not in ring $s$ around county $m$, and $1 /(\#$ counties in ring $s$ around county $m$ ) for every county within the ring. We also allow for conditional heteroskedasticity in the variance of the shock $e_{m t}$, i.e., $\operatorname{var}\left(e_{m t} \mid \mathbf{X}_{t}\right)=\exp \left\{\delta_{m}^{(0)}+\mathbf{X}_{m t} \boldsymbol{\delta}^{(1)}\right\}$, where $\delta_{m}^{(0)}$ is county-fixed-effect, and $\boldsymbol{\delta}^{(1)}$ is a vector of parameters.

Given this factor model, it is straightforward to show that the vector with the logarithm of deposits per-branch for each county at year $t$ has the following vector of expected values and variance-covariance matrix:

$$
\begin{aligned}
\boldsymbol{\mu}_{t} & \equiv \mathbb{E}\left(\ln \mathbf{d}_{t} \mid \mathbf{X}_{t}\right)=\boldsymbol{\alpha}^{(0)}+\mathbf{X}_{t} \boldsymbol{\alpha}^{(1)} \\
\boldsymbol{\Omega}_{t} \equiv \mathbb{V}\left(\ln \mathbf{d}_{t} \mid \mathbf{X}_{t}\right) & =\mathbf{X}_{t} \mathbf{B} \boldsymbol{\Sigma}_{\mathbf{f}} \mathbf{B}^{\prime} \mathbf{X}_{t}^{\prime}+(I-\boldsymbol{\rho} \mathbf{W})^{-1} \mathbf{D}\left(\boldsymbol{\delta}, \mathbf{X}_{t}\right)\left(I-(\boldsymbol{\rho} \mathbf{W})^{\prime}\right)^{-1}
\end{aligned}
$$

where $\boldsymbol{\alpha}^{(0)}$ is the vector of $M$ county fixed-effects $\left(\alpha_{1}^{(0)}, \alpha_{2}^{(0)}, \ldots, \alpha_{M}^{(0)}\right)^{\prime} ; \boldsymbol{\rho} \mathbf{W}$ is the matrix $\rho_{1} \mathbf{W}_{1}+$ $\rho_{2} \mathbf{W}_{2}+\ldots+\rho_{S} \mathbf{W}_{S}$; and $\mathbf{D}\left(\boldsymbol{\delta}, \mathbf{X}_{t}\right)$ is a $M \times M$ diagonal matrix with elements $\exp \left\{\delta_{m}^{(0)}+\mathbf{X}_{m t} \boldsymbol{\delta}^{(1)}\right\}$.

\section{Data and descriptive evidence}

\subsection{Data}

We focus on the period following the passage of the RN Act, specifically the period from 1994 to 2006. Counties, the primary administrative divisions for most states, are chosen as our market definition. There are 3,141 counties in the 50 states and the District of Columbia. The boundaries of counties have been generally static in recent years. ${ }^{10}$ By contrast, the boundaries of cities, villages, and other incorporated locations have been far more subject to changes. In our context, a county serves as a convenient, time invariant geographic unit at which level we can easily combine

\footnotetext{
${ }^{10}$ For rare cases where boundaries of counties do alter, the changes are minor and do not involve significant shifts of population or land area. For more detailed information about the history and summary description of the counties in the U.S., refer to the Chapter 4 of "Geographic Areas Reference Manual" of the Census Bureau, available at http://www.census.gov/geo/www/garm.html.
} 
the branching activities of the depository institutions with detailed local demographic, social, and economic information.

Our branch level information comes from the Summary of Deposit (SOD) data provided by the Federal Deposit Insurance Corporation (FDIC). The SOD dataset is collected on June 30th each year, covering all institutions insured by the FDIC, including commercial banks and saving associations. The dataset includes information, at the individual branch level, on deposits, address, and bank affiliation. Based on the county identifier of each branch, we can construct a measure of the number of branches and total deposits for each bank in each county. ${ }^{11}$

The US Census Bureau provides various data products through which we obtain detailed county level characteristics to estimate our model: (1) population counts by age, gender, and ethnic group are obtained from the Population Estimates; (2) median household income at the county level is extracted from the State and County Data Files, while income per capita is provided by the Bureau of Economic Analysis (BEA); (3) information on local business activities such as two-digit-industry level employment and number of establishments is provided by the County Business Patterns; (4) detailed geographic information, including the area and population weighted centroid of each county, and locations of the landmarks in the US, is obtained from the Topologically Integrated Geographic Encoding and Referencing system (TIGER) dataset. ${ }^{12}$

We derive bank level characteristics from balance sheets and income statement information in the banks' quarterly reports provided to the different regulatory bodies: the Federal Reserve Board (FRB)'s Report on Condition and Income (Call Reports) for commercial banks, and the Office of Thrift Supervision (OTS)'s Thrift Financial Report (TFR) for saving associations.

The National Information Center records the timing of major historical events, such as renaming, merger and acquisition, and bankruptcy, of all depository institutions that ever existed in the United States. This information allows us to identify all the merger cases and the involved banks during the sample period.

\subsection{Descriptive evidence}

Tables 1 and 2 and figures 1 to 3 present a description of the evolution of branch networks in the US banking industry during the period 1994-2006. These are the main stylized facts:

(i) Consolidation and wave of mergers. There has been significant consolidation of the industry, as shown by the massive and continued reduction in the number of commercial banks. The rate of decline in the number of banks slowed down during the later years of the sample. Most of the reduction in the number of banks has taken place through mergers and very little is explained by

\footnotetext{
${ }^{11}$ A small proportion of branches in the SOD dataset (around $5 \%$ of all branches) have zero recorded deposits. These might be offices in charge of loans or administrative issues. We exclude them in our analysis.

${ }^{12}$ To measure the geographic distance between two counties we use the population-weighted centroid of each county and the Haversine formula (Sinnott 1984) to account for Earth curvature.
} 
bank failures. Despite the significant reduction in the number of banks, there were still almost nine thousand banks in 2006. ${ }^{13}$ Figure 1 presents the time series for the annual number of bank mergers and the proportion of within-state mergers during the period 1976-2006. This figure shows that the process of consolidation started in the early 1980s with a strong wave of bank mergers that reached its peak in 1988-92.

(ii) Growth in number of branches. Despite the decline in the number of banks, the number of branches has experienced continuous growth over our sample period, from 80,795 branches in 1994 to 94,123 in 2006. The average number of branches per bank has grown from 6.3 in 1994 to 10.8 in 2006. Population and wealth growth have increased demand for commercial banking services. This, together with the existence of capacity constraints at the branch level, explains part of the rising number of branches. Another factor is that the deregulation of the industry, and in particular the enactment of RN, has eliminated barriers to entry and have encouraged competition and entry of other banks. Consistent with this hypothesis, table 1 shows that banks with headquarters in other state have been very active in the creation of new branches. Between 1997 and 2006, these banks account for between $21 \%$ and $33 \%$ of all denovo branches, despite the fact that they represent a much smaller fraction of all banks.

(iii) Growth through mergers and denovo branches. The growth in the size of commercial banks, as measured by the number of branches per bank, has taken place both through the acquisition of other banks and through denovo branching. Table 1 shows that between half and two-thirds of branch creation is accounted for by mergers and acquisitions. ${ }^{14}$ This proportion is between $66 \%$ and $91 \%$ in states other than the bank's headquarters, and between $33 \%$ and $50 \%$ within the same state. Therefore, while most of the out-of-state expansion has occurred through mergers, the within-state expansion has been both through mergers and denovo branching. ${ }^{15}$

(iv) Geographic expansion. Figure 2 shows how the proportion of multi-state banks has grown steadily during the sample period. The growth is concentrated in larger banks, as measured either

\footnotetext{
${ }^{13}$ The number of banks has continued declining between 2006 and 2010. According to a FDIC report from April 14, 2010, the number of FDIC-insured banks was 7,731. However, in contrast to our period of analysis, a significant component of the decline since 2008 is due to bank failures.

${ }^{14}$ Here we define branch creation in the same way as Davis and Haltiwanger (1992) defined job creation and job destruction. Total branch creation at period $t$ is equal to $\sum_{i=1}^{I_{t}} \sum_{m=1}^{M} 1\left\{\Delta n_{\text {imt }}>0\right\} \Delta n_{\text {imt }}$, where $1\{$.$\} is the binary$ indicator function, and $\Delta n_{i m t} \equiv n_{i m t}-n_{i m t-1}$ is the change in the number of branches between years $t-1$ and $t$. Branch creation accounted for by mergers and acquisitions is equal to $\sum_{i=1}^{I_{t}} \sum_{m=1}^{M} 1\left\{\Delta n_{i m t}^{M}>0\right\} \Delta n_{i m t}^{M}$, where $\Delta n_{i m t}^{M}$ is the change due to a merger or acquisition. Appendix A describes our approach to identify which part of the annual variation in the number of branches of a bank in a county is associated with a merger and which part is due to denovo branching.

${ }^{15}$ While almost every state immediately adopted RN to allow for inter-state banking through mergers, some states still have not chosen to permit inter-state banking through de novo branching. These surviving restrictions may have had an effect on the way banks enter in other states. Twenty-four states adopted intestate branching by merger/acquisition between 1994 and 1996, and twenty-five states adopted it on the deadline of June 1st 1997. Only two states, Texas and Montana, opted out by that deadline, but they subsequently adopted interstate branching by merger in 1999 and 2002, respectively. Interstate branching via de novo establishment had to be opted into specifically. As of 1997, only thirteen states allowed de novo, and by 2005 twenty-two did.
} 
by number of branches or by volume of deposits. Despite this growth, the proportion of "large" banks operating in multiple states is less than $20 \%$ in 2006.

(v) Distribution of deposits per branch. Table 2 presents the distribution of deposits per-branch in 1994, in millions of 1990 dollars. The sample median is $\$ 20.2$ million and more than $90 \%$ of the counties have deposits per branch between $\$ 10$ million and $\$ 40$ million. This low dispersion in the size of branches, despite the large heterogeneity in the market sizes of counties, suggests that branches face substantial diseconomies of scale when growing in size such that, to accommodate an increase in consumer supply of deposits, most of the adjustment takes place through an increase in the number of branches. Figure 3 presents the cross-sectional distribution of the logarithm of deposits per branch for the 3,101 counties for years 1994, 1996, 1998, 2002, and 2006. This distribution has been very stable over the period 1994-2006. This time-stability in the distribution of branch size, despite total deposits in real terms increasing by $51 \%$ during this period, shows again that banks have adjusted to this increase in supply of deposits almost entirely using the extensive margin, i.e., increasing the number of branches.

\section{Evolution of bank geographic risk from deposits}

In this section we present our estimates of the factor model, and use these estimates to determine (i) the extent to which banks can diversify their geographic risk, and (ii) the extent to which banks did diversify their risk.

\subsection{Estimation of the factor model}

Table 3 summarizes the estimation of the factor model. ${ }^{16}$ The number of observations in the estimation is 37, 200 (3100 counties times 12 years). The vector of market characteristics $\mathbf{X}_{m t}$ includes 44 variables at the county level: lagged depend variable, lagged number of branches, log population, log income-per-capita, log total-employment, log number of establishments, employment shares of nineteen 2-digit industries, and establishment shares of nineteen 2-digit industries. Therefore, taking into account the interactions with the time dummies, the vector of regressors $\mathbf{X}_{m t}^{*}$ and the vector of parameters $\gamma$ have 499 elements. The goodness-of-fit of the model is excellent: the Rsquare coefficient for the within-groups regression is 0.54 , and the equation in levels (including fixed effects) has an R-square of 0.87 .

Panel 3(a) includes estimates of the parameters $\boldsymbol{\alpha}^{(0)}$ and $\boldsymbol{\alpha}^{(1)}$ in the mean value of log-depositsper-branch. We report estimates of the most significant parameters $\boldsymbol{\alpha}^{(1)}$, and several quantiles in the empirical distribution of the county fixed effects $\alpha_{m}^{(0)}$. There is substantial persistence in the logarithm of deposits per-branch even after controlling for county fixed effects: the parameter

\footnotetext{
${ }^{16}$ See Appendix B for a description of the estimation procedure.
} 
estimate for the lagged dependent variable is 0.7382 (s.e. =0.0067). As expected, deposits per branch increase significantly with population, income per capita, and employment in the county. The employment share of industries such as Management, Real Estate, IT, and Retail, have a positive effect on deposits-per-branch. The distribution of county fixed effects shows significant heterogeneity in expected returns across counties that is not explained by the included observable variables.

Panel 3(b) presents summary statistics on the estimation of systematic risk, as measured by $\sqrt{\mathbf{X}_{m t} \mathbb{V}\left(\widehat{\gamma}_{t}\right) \mathbf{X}_{m t}^{\prime}}$. We report measures of systematic risk averaged over all of the counties for the year 1995. The amount of systematic risk is substantial. Most of this risk is accounted for by the factor associated with log income (47\%). The factors related to the employment shares of 2-digit industries $(14 \%)$ also represent important contributions to systematic risk. ${ }^{17}$

Panel 3(c) presents estimates of the parameters in the spatial autoregressive process of residuals. We consider four bands around the geographic centroid of a county: 200 miles, 200 to 400 miles, 400 to 1,000 miles, and more than 1,000 miles. There is very significant positive spatial correlation in the residuals. This spatial dependence declines with distance, and becomes insignificant for a distances greater than 1,000 miles. Panel 3(d) presents the estimated parameters in the model for the variance of the diversifiable risk. Most of the heterogeneity across counties in diversifiable risk is captured by county fixed effects. After controlling for these fixed effects, the contribution of time-varying observables to diversifiable risk is small and not statistically significant.

Figures 4, 5, and 6 present the cross-sectional distributions of expected log-deposits-per-branch, systematic risk, and diversifiable risk based on the estimates of the factor model. These crosssectional distributions have been very stable over the whole sample period. Furthermore, these variables are very persistent over time for almost every county, i.e., counties with high levels of systematic or diversifiable risk in 1996 also have high levels of risk in 2006.

For most counties, the estimated level of deposits risk is substantial. For 90\% of the counties, systematic risk is between 0.6 and 2.3 percentage points (i.e., percentiles 10 and 90, respectively) and diversifiable risk is between 1.1 and 3.1 percentage points.

\subsection{Geographic Risk Diversification possibilities-Efficient frontiers}

We start by considering the possibilities for geographic risk diversification (GRD) available to banks before and after RN. We use the factor model estimated above to construct efficient frontiers for each state in 1995 before the banks could take advantage of RN, and a single efficient frontier in 2006 assuming banks can locate branches anywhere in the United States. A bank portfolio is its branch network $\mathbf{n}_{i t}$. Let $\mathbf{w}_{i t} \equiv\left\{w_{i m t}: m=1,2, \ldots, M\right\}$ be the vector of asset shares in the portfolio of bank $i$ such that $w_{i m t} \equiv n_{i m t} /\left(\sum_{m^{\prime}=1}^{M} n_{i m^{\prime} t}\right)$. By expected return and risk of a bank branch

\footnotetext{
${ }^{17}$ The decomposition of the contribution of different factors does not sum to $100 \%$ because non-zero covariances.
} 
portfolio we mean $R_{i t} \equiv \mathbf{w}_{i t}^{\prime} \boldsymbol{\mu}_{t}$ and $S_{i t} \equiv \sqrt{\mathbf{w}_{i t}^{\prime} \boldsymbol{\Omega}_{t} \mathbf{w}_{i t}^{\prime}}$, respectively. A portfolio lying on the efficient frontier represents the combination of counties in a given state offering the best possible expected return for given level of risk. For the moment, the construction of these efficient frontiers is based on the assumption that all portfolios of counties are feasible, i.e. that banks can open 'many' branches in a state and locate them optimally throughout all of the counties. Given this, the Efficient Frontier informs us as to the possibilities of diversification only for large banks. ${ }^{18}$

(a) Prior to Riegle Neal. Figure 7 presents the efficient frontiers for each of the states ordered according to their maximum return-to-risk ratios. The figure reveals very significant cross-State heterogeneity in the pre RN frontiers. The observed heterogeneity implies that the possibilities for geographic risk diversification for very large banks differed significantly across states. Therefore, in some states large banks could easily achieve a diverse portfolio of branches while in others they would have been constrained by the limitations of the pre RN regulations.

To understand the relationship between state socioeconomic characteristics and Efficient Frontiers, we have run several regressions using State level data where the dependent variable is a feature of the state Efficient Frontier, such as Minimum Risk, Maximum Return-to-Risk-Ratio, or Maximum Return, and the set of explanatory variables are measures of the State geographic, demographic, and economic size such as number of counties, area, population, income, number of establishments, and of the within State geographic dispersion in population, income, and business activity. ${ }^{19}$ The most significant effect, both economically and statistically comes from the number of counties in the state. We find that, ceteris paribus, states with more counties tend to have larger maximum return-to-risk ratios and smaller Minimum Risk.

(b) Post Riegle Neal. Figure 8 plots the 2006 Efficient Frontier assuming banks can locate branches anywhere in the US. The comparison of this frontier with the pre RN frontier of a small state like Maryland shows that the possibilities for risk diversification improved dramatically for large banks located in small states. The comparison with a large state like Texas shows more moderate improvements. Table 4 reports the percentage change in maximum return-to-risk and minimum risk in the Efficient Frontier for each state resulting from RN. On average, the risk of an efficient portfolio declined 0.6 percentage points, ${ }^{20}$ which represents about a 1 standard deviation decline relative to the efficient risk in 1995. The improvement is particularly important for states with restrictive frontiers prior to deregulation.

\footnotetext{
${ }^{18}$ More precisely, in the construction of these frontiers we assume that the weight of county $m$ in the portfolio of bank $i$, as measured by the ratio $n_{i m t} /\left(\sum_{m^{\prime}=1}^{M} n_{i m^{\prime} t}\right)$ is a continuous variable. This is a good approximation to the actual choice of a bank only when its total number of branches is large.

${ }^{19}$ For the sake of space, we do not report these estimates in the paper.

${ }^{20}$ We calculate the levels of risk before and after RN for market $m$, and then take the average of the difference of these two values across counties.
} 


\subsection{Geographic Risk Diversification possibilities-small banks}

(a) Prior to Riegle Neal. The efficient frontiers presented above describe the geographic risk diversification possibilities only for large banks since their construction is based on the assumption that banks can open a continuum of branches and locate them optimally throughout all of the counties in a given state. Most banks do not have a very large number of branches and the frontier for a continuum of branches might not be a realistic constraint for them. In this section we seek evidence on the possibilities of GRD pre RN for banks with a relatively small number of branches and with a "home county bias". Our evidence is based on the following 'thought experiment'. We suppose that a bank has a single branch in county $m$. We then suppose that this bank can open $n-1$ more branches anywhere within the state, but that it must maintain its original branch in county $m$. We suppose that these branches are added sequentially with each additional branch added in such a way as to maximize the return-to-risk ratio taking as given the location of the previous existing branches. We then ask the following questions: (i) What is the maximum return-to-risk ratio that this bank can reach when it adds $n-1$ branches optimally? (ii) What is the minimum level of risk that this bank can achieve when it adds $n-1$ branches optimally?

We implement this 'thought experiment' for every US county using the expected returns and variance matrix of 1995. Then we construct the following statistics at the state level: the median of the maximum return-to-risk ratio, and the median of the minimum possible risk level if $n=1$, $n=5$, and $n=10$. We compare these statistics between states to learn about heterogeneity in the possibilities of GRD for small banks prior to RN. Table 5 presents statistics for Minimum Risk. For almost every state, small banks can achieve significant benefits from within-state GRD. In every state, with the exception of Hawaii and New Hampshire, opening a second branch reduces the minimum risk by more than 1.0 percentage point, and in most states by more than 1.5 percentage points. There is further benefit to adding more branches, but the benefit is decreasing in the number of branches. Second, there are significant differences across states in the benefits of within-state GRD for small banks. For instance, the reduction in minimum risk associated with a network expansion from 1 to 5 branches is less than one percentage point for states such as Hawaii (0.5), Rhode Island (0.5), Delaware (0.8), Maine (0.9), or New Hampshire (0.98), but is above two percentage points for states like Colorado (2.4), Alaska (2.3), or Virginia (2.0).

(b) Post Riegle Neal. To study the possibilities for GRD post RN for smaller banks we repeat the thought experiment performed above, but now assume that in addition to being able to locate inside their home state banks can expand beyond state borders. This provides banks with more options for diversifying their risk. For simplicity of calculation we assume that banks can only expand to contiguous states. This is a lower bound on the benefits from RN since the Act allows banks not only to expand into contiguous states, but into any state in the country. Table 6 presents the percentage difference in maximum return-to-risk ratio (MaxRR) and minimum risk (MinRisk) 
pre $\mathrm{RN}$ and post RN for a bank with only 5 branches. The percentage changes in MaxRR and MinRisk are calculated for each county and the reported numbers are the median values of counties for each state. As in the case of large banks, we also find substantial heterogeneity in the effects of $\mathrm{RN}$ on the possibilities of GRD of small banks. In some states there is little benefit to being able to expand to neighboring states: Texas (change in MaxRR is $5.8 \%$, and change in MinRisk is $-6.7 \%$ ), California (8.1\% and $-9.2 \%)$, or Wisconsin $(3.6 \%$ and $-2.3 \%)$. However, the effect in other states is very considerable: Massachusetts ( $81.3 \%$ and $-46.8 \%)$, Nevada (80.3\% and $-32.2 \%)$, Maryland ( $75.7 \%$ and $-39.5 \%)$, Delaware $(58.8 \%$ and $-40.8 \%)$, or Rhode Island $(34.9 \%$ and $-32.2 \%)$.

\subsection{Actual bank portfolios}

So far we have talked only about the possibilities for geographic risk diversification in different states before and after RN. Here we study actual bank portfolios in an effort to learn about the extent to which banks were diversified at the time of $\mathrm{RN}$ and whether this is the result of the constraints imposed on expansion prior to its implementation.

We start by looking at actual banks' portfolios prior to RN. Using the vector of means and the variance matrix of deposits per-branch of 1995, we obtain the expected return, $R_{i}$, and the risk, $S_{i}$, for each bank in 1995. In figures $9 \mathrm{~A}$ and $9 \mathrm{~B}$ we present the cross-sectional distributions of banks' expected returns and risk. The comparison of these distributions at the bank level with the corresponding distributions at the county level (in figures 4 to 6) shows that, despite the modest geographic spread of bank networks in 1995, bank risk is substantially smaller than county risk (i.e., their medians are $2.4 \%$ and $3.5 \%$, respectively). In contrast, the distributions of expected returns at bank and county level are very similar.

Figure 10 presents the cross-sectional distribution of expected return (panel A), and risk level (panel B) for 1995 and for 2006. We can see that there is some improvement in expected return (i.e., the median value goes from 3.17 to 3.19 , an improvement of 2 percentage points), but almost no reduction in risk (i.e., the median value goes from 0.0230 to 0.0226 , a reduction in 0.04 percentage points).

The evidence presented so far suggests that bank deposits risk decreased very little between 1995 and 2006. We are interested in determining what part of the change in bank risk can be attributed to RN and what part stems from other factors. In principle, it is possible that exogenous changes in the distribution of county risk, or within-state changes in bank networks, may have offset the effects of RN on banks' risk. In order to disentangle the contribution of $\mathrm{RN}$, in what follows we present results from a counterfactual decomposition of the change in the empirical distribution of bank risk and return between 1995 and 2006.

A cross-sectional distribution of banks' risk, either factual or counterfactual, can be described as a vector of banks' risks $\mathbf{P} \equiv\left\{S_{i}: i \in I\right\}$ where $I$ is a set of banks, and $S_{i}$ is the risk of bank $i$. Since 
the risk of bank $i$ is determined by the function $S_{i}=\sqrt{\mathbf{n}_{i}^{\prime} \boldsymbol{\Omega} \mathbf{n}_{i}}$, we have that we can represent a cross-sectional distribution of banks' risks as a function $\mathbf{P}=f(\boldsymbol{\Omega}, I, \mathbf{n})$. If the values of the matrix $\boldsymbol{\Omega}$, the set of banks $I$, and the banks' branch networks $\left\{\mathbf{n}_{i}\right\}$ correspond to their actual values in a particular year $t$, then we have the factual distribution of risks in that year, i.e., $\mathbf{P}_{t}=f\left(\boldsymbol{\Omega}_{t}, I_{t}, \mathbf{n}_{t}\right)$. Otherwise, we have a counterfactual distribution of risks. Using function $f($.$) , we can decompose$ the actual change in the distribution of banks' risks between years 1995 and $2006, \mathbf{P}_{06}-\mathbf{P}_{95}$, into the contribution of three counterfactual changes:

$$
\begin{aligned}
\mathbf{P}_{06}-\mathbf{P}_{95} & =\left[f\left(\boldsymbol{\Omega}_{06}, I_{95}, \mathbf{n}_{95}\right)-f\left(\boldsymbol{\Omega}_{95}, I_{95}, \mathbf{n}_{95}\right)\right] \Rightarrow \text { Contribution of change in } \boldsymbol{\Omega} \\
& +\left[f\left(\boldsymbol{\Omega}_{06}, I_{06}^{I N}, \mathbf{n}_{06}^{I N}\right)-f\left(\boldsymbol{\Omega}_{06}, I_{95}, \mathbf{n}_{95}\right)\right] \Rightarrow \text { Contribution of within-state expansion } \\
& +\left[f\left(\boldsymbol{\Omega}_{06}, I_{06}, \mathbf{n}_{06}\right)-f\left(\boldsymbol{\Omega}_{06}, I_{06}^{I N}, \mathbf{n}_{06}^{I N}\right)\right] \Rightarrow \text { Contribution of out-state expansion. }
\end{aligned}
$$

This decomposition captures three different ceteris paribus effects. The first term measures the contribution of the change in matrix $\boldsymbol{\Omega}$ between 1995 and 2006. $f\left(\boldsymbol{\Omega}_{06}, I_{95}, \mathbf{n}_{95}\right)$ is the counterfactual distribution that we would observe if the set of banks and their branch networks were the ones in 1995 , but we had the variance matrix of risks of 2006. Therefore, the difference $\left[f\left(\boldsymbol{\Omega}_{06}, I_{95}, \mathbf{n}_{95}\right)\right.$ $\left.-f\left(\boldsymbol{\Omega}_{95}, I_{95}, \mathbf{n}_{95}\right)\right]$ measures the ceteris paribus contribution of the change in $\boldsymbol{\Omega}$. The second term measures the ceteris paribus effect of within-state branch expansion and mergers. In the counterfactual distribution $f\left(\boldsymbol{\Omega}_{06}, I_{06}^{I N}, \mathbf{n}_{06}^{I N}\right)$, the arguments $I_{06}^{I N}$ and $\mathbf{n}_{06}^{I N}$ represent the set of banks and the vector of branch networks in 2006, respectively, if we eliminate any bank expansion outside the home state, i.e., we eliminate mergers between banks with different home states, and "close" branches opened in states other than the home state of the bank. The third term captures the ceteris paribus effect of out-of-state branch expansion and mergers. This is because the difference between $\left\{I_{06}, \mathbf{n}_{06}\right\}$ and $\left\{I_{06}^{I N}, \mathbf{n}_{06}^{I N}\right\}$ captures banks' expansion outside their home state either through mergers of denovo branching. ${ }^{21}$

Results are presented in figures 11 and 12 for the distributions of risk and expected return, respectively. The first row shows the actual change in the distribution. Rows 2 to 4 present the contribution to the actual change of the variation in the omega matrix, within-state expansion, and out-state expansion, respectively. These figures show that out-of-state branch expansion did not have any contribution to the reduction in bank risk but it contributed to increase expected returns. Almost all the small reduction in risk comes from within-state branch expansion. During the post $\mathrm{RN}$ period, a substantial fraction of banks reduced their risk by expanding geographically within the limits of their states. As we have shown above, for most states (except a group of small states predominantly located in the East coast), in 1995 there were important benefits from within-state GRD that had not been exploited by most banks. The evidence suggests that between 1995-2006

\footnotetext{
${ }^{21}$ For the construction of the counterfactual sets of banks and branch networks $\left\{I_{06}^{I N}, \mathbf{n}_{06}^{I N}\right\}$, we need to make some assumptions. We describe these assumption in Appendix D.
} 
many banks in these states have taken advantage of the possibilities for GRD afforded them through within-state expansion. As illustrated in figure 1, this process of within-state bank expansion and consolidation via mergers is not new, and has been an ongoing process since the 1980s.

\section{Estimation of Bank Preferences}

We have shown that RN implied a substantial improvement in the possibilities of GRD for many banks with headquarters in small states, but that most of these banks did not take advantage of these possibilities. One explanation for this finding is that banks are not seriously concerned about geographic diversification of deposits risk. An alternative explanation is that other factors, such as diseconomies of scale, economies of density, merging costs, and local market power have counterbalanced banks' concern for GRD. In this section, our objective is to quantify banks' concern for geographic diversification of risk, and to identify it separately from other factors that influence branch network expansion. Our measure of bank geographic risk, based on the estimated factor model, plays a key role in this identification. This risk measure has substantial sample variation across banks after controlling for the number of branches in bank networks (i.e., economies of scale), and for the geographic distance between these branches (i.e., economies of density). This is because banks' networks have home counties or regions with different levels of risk, as estimated in the factor model. We observe that most banks expand their networks around their home county, and we find that this pattern is explained by economies of density. We also observe that banks located in home counties with higher levels of risk, or/and surrounded by counties with relatively lower risk, have a greater propensity to expand geographically. We find that this evidence is explained by banks' concern with reducing geographic risk.

\subsection{Specification of bank preferences}

The specification of the value of a bank comes from our model in section 2 , and more specifically from equation (4). To complete this specification for the purpose of estimation, we should specify the functional forms of the cost functions $F C_{i t}$ and $A C_{i t}$, and of the cost of insolvency. $F C_{i t}\left(\mathbf{n}_{i t}\right)$ is a fixed operating cost that captures economies of scale and density in the operation of a branch network. It depends on the total number of branches in the network, and on the average distance between these branches. We consider a quadratic specification in terms of the number of branches (i.e., $\theta_{1}^{F C}$ [\#branches] $+\theta_{2}^{F C}$ [\#branches $]^{2}$ ) and of the average distance to the bank's headquarters (i.e., $\theta_{3}^{F C}$ [\#branches * distance-to-HQs] $+\theta_{4}^{F C}$ [\# branches $*\left(\right.$ distance-to-HQs) $\left.\left.{ }^{2}\right]\right) . A C_{i t}\left(\mathbf{n}_{i t}, \mathbf{n}_{i t-1}\right)$ represents costs of expanding the branch network. It depends on the change in total number of branches of the bank, on the form of expansion (through merger or denovo branching), and on

whether the expansion is within or outside the headquarters state of the bank: i.e., $\theta_{1}^{A C}$ [\# new branches via denovo, within HQs state $]+\theta_{2}^{A C}$ [\# new branches via denovo, outside HQs state] + 
$\theta_{3}^{A C}[\#$ new branches via merger, within HQs state $]+\theta_{4}^{A C}[\#$ new branches via merger, outside HQs state].

As for the exogenous variable $\rho_{i t}$ that captures the cost in case of bank insolvency, we consider that it is proportional to the expected variable profit of the bank. Therefore, the expected value of a bank network becomes $\mathbb{E}\left(V_{i t} \mid \mathbf{X}_{t}\right)=\left(1-\bar{\rho} \Phi_{i t}\right) \mathbb{E}\left(\sum_{m=1}^{M} \pi_{i m t} \mid \mathbf{X}_{t}\right)-F C_{i t}-A C_{i t}$, where $\Phi_{i t}$ is the probability of insolvency, and the parameter $\bar{\rho}$ can be interpreted as an ad-valorem tax, i.e., a probability of insolvency $\Phi_{i t}$ is equivalent to a tax $\bar{\rho} \Phi_{i t}$ on variable profits.

For the estimation of the model, it is very convenient that the expected value of a bank can be represented as an index that is linear in the parameters to estimate, $\boldsymbol{\theta}$, i.e., $\mathbb{E}\left(V_{i t} \mid \mathbf{X}_{t}\right)=W_{i t} \boldsymbol{\theta}$, where $W_{i t}$ is a vector of observable explanatory variables. Our specification has this structure except for the parameter $\gamma_{2}^{(D)} / \beta^{(D)}$ that enters in the weighting function $w_{i}^{(D)}\left(\mathbf{n}_{m t}\right)$ (see equation (2)) and in the bank's expected deposits and variables profits. This parameter determines how the volume of deposits of a bank in a local market increases with its own number of branches (and declines with competitor branches). We estimate this parameter using the first order condition of profit maximization in the Cournot competition model. This condition, after a logarithm transformation, has the following expression:

$$
\ln \left(d_{i m t}\right)=\ln \left(\frac{r_{t}^{(B)}-\alpha_{m t}^{(D)}-\gamma_{1 m t}}{\beta^{(D)}}\right)-\ln \left(1+\frac{\gamma_{2}^{(D)}}{\beta^{(D)}} \frac{1}{n_{i m t}}\right) .
$$

And based on this equation, we estimate panel data regression model $\ln \left(d_{i m t}\right)=X_{m t} \beta-\left(\gamma_{2}^{(D)} / \beta^{(D)}\right)$ $\left(1 / n_{\text {imt }}\right)+e_{i m t}$, where the vector of exogenous regressors $X_{m t}$ is the same in our estimation of the factor model. ${ }^{22}$ We include time dummies, county dummies, and deal the endogeneity of $\left(1 / n_{\text {imt }}\right)$ by using Arellano-Bond instrumental variables. More precisely, we use lagged values of $\left(1 / n_{\text {imt }}\right)$ as instruments. For the sake of space, we do not report here a complete table of estimates. Our preferred estimate of the parameter of interest $\gamma_{2}^{(D)} / \beta^{(D)}$ is 0.769 (s.e. $=0.181$ ), and this estimate implies that a bank's deposits in a local market increases by $34 \%$ (i.e., $0.769 / 2$ ) when the bank's number of branches goes from one to two. We plug-in this estimate of $\gamma_{2}^{(D)} / \beta^{(D)}$ in function $w_{i}^{(D)}\left(\mathbf{n}_{m t}\right)$ to obtain expected variable profits and deposits.

The expected value of bank $i$ at period $t$ is represented as $W_{i t}\left(\mathbf{n}_{i t}\right) \boldsymbol{\theta}+\varepsilon_{i t}\left(\mathbf{n}_{i t}\right)$, where $W_{i t}\left(\mathbf{n}_{i t}\right)$ is a vector of known functions and $\boldsymbol{\theta}$ is the vector $\left(1, \bar{\rho}, \theta_{1}^{F C}, \theta_{2}^{F C}, \theta_{3}^{F C}, \theta_{4}^{F C}, \theta_{1}^{A C}, \theta_{2}^{A C}, \theta_{3}^{A C}, \theta_{4}^{A C}\right)^{\prime}$, $\varepsilon_{i t}\left(\mathbf{n}_{i t}\right)$ represents the effect of other factors that are unobservable to the researcher, but known to the bank.

\footnotetext{
${ }^{22}$ This equation provides a simple and intuitive interpretation of the parameter $\gamma_{2}^{(D)} / \beta^{(D)}$. This parameter represents the percentage increase in a bank's deposits in a local market when the bank's number of branches goes from one branch to an arbitrarily large number of branches. Also, the parameter $(1 / 2) *\left(\gamma_{2}^{(D)} / \beta^{(D)}\right)$ represents the percentage increase in the bank's deposits when its number of branches goes from one to two.
} 


\subsection{Estimation method}

We apply the principle of revealed preference to estimate the vector of parameters $\boldsymbol{\theta}$. We assume that every year $t$, bank $i$ chooses its network $\mathbf{n}_{i t}$ to maximize its value:

$$
\mathbf{n}_{i t}=\arg \max _{\mathbf{n} \in A_{i t}}\left\{W_{i t}(\mathbf{n}) \boldsymbol{\theta}+\varepsilon_{i t}(\mathbf{n})\right\}
$$

where $A_{i t}$ is the set of feasible networks for bank $i$ at year $t$. We estimate the structural parameters of our model using a Moment Inequalities estimator (MIE). Let $\boldsymbol{\theta}^{0}$ be the 'true' value of the vector of structural parameters. Revealed preference implies that the value of a bank from its actual choice $\mathbf{n}_{i t}$ cannot be smaller than the value of that bank for any other feasible choice of network. That is, for any vector $\mathbf{n}$ in the feasible set $A_{i t}, W_{i t}\left(\mathbf{n}_{i t}\right) \boldsymbol{\theta}^{0}+\varepsilon_{i t}\left(\mathbf{n}_{i t}\right) \geq W_{i t}(\mathbf{n}) \boldsymbol{\theta}^{0}+\varepsilon_{i t}(\mathbf{n})$. These inequalities still hold when we integrate the two sides over the distribution of $\varepsilon_{i t}$ conditional on the observable predetermined state variables $\mathbf{X}_{t}$ :

$$
\mathbb{E}\left(W_{i t}\left(\mathbf{n}_{i t}\right) \frac{\boldsymbol{\theta}^{0}}{\sigma_{\varepsilon}}+\frac{\varepsilon_{i t}\left(\mathbf{n}_{i t}\right)}{\sigma_{\varepsilon}}-W_{i t}(\mathbf{n}) \frac{\boldsymbol{\theta}^{0}}{\sigma_{\varepsilon}}-\frac{\varepsilon_{i t}(\mathbf{n})}{\sigma_{\varepsilon}} \mid \mathbf{X}_{t}\right) \geq 0,
$$

and $\sigma_{\varepsilon}$ is the standard deviation of the unobservables $\varepsilon_{i t}(\mathbf{n})$. By assumption, for an arbitrary choice $\mathbf{n}$ the variables $\mathbf{X}_{t}$ and $\varepsilon_{i t}(\mathbf{n})$ are independently distributed. Therefore, we have that $\mathbb{E}\left(\varepsilon_{i t}(\mathbf{n}) \mid \mathbf{X}_{t}\right)=0$. However, the value of $\varepsilon_{i t}\left(\mathbf{n}_{i t}\right)$ associated with the actual/optimal choice $\mathbf{n}_{i t}$ is not independent of $\mathbf{X}_{t}$. Under the assumption that the variables $\left\{\varepsilon_{i t}(\mathbf{n})\right\}$ are i.i.d. extreme value distributed, we have that $E\left(\varepsilon_{i t}\left(\mathbf{n}_{i t}\right) \mid \mathbf{X}_{t}\right)=\sigma_{\varepsilon}\left(\gamma-\ln \operatorname{Pr}\left(\mathbf{n}_{i t} \mid \mathbf{X}_{t}\right)\right)$, where $\gamma$ is Euler's constant. Therefore, we can write the following system of unconditional moment inequalities that includes only observable variables and unknown parameters:

$$
\mathbb{E}\left(\mathbf{Z}_{i t}\left[\widetilde{W}_{i t}(\mathbf{n}) \frac{\boldsymbol{\theta}^{0}}{\sigma_{\varepsilon}}+\gamma-\ln \operatorname{Pr}\left(\mathbf{n}_{i t} \mid \mathbf{X}_{t}\right)\right]\right) \geq 0
$$

where $\widetilde{W}_{i t}(\mathbf{n}) \equiv\left[W_{i t}\left(\mathbf{n}_{i t}\right)-W_{i t}(\mathbf{n})\right]$, and $\mathbf{Z}_{i t}$ is a vector of instruments, i.e., known functions of predetermined state variables $\mathbf{X}_{t}$ and of exogenous bank characteristics. Following Chernozukov, Hong, and Tamer (2007), for the estimation of $\boldsymbol{\theta}^{0}$ we choose a value that minimizes a sample criterion function that penalizes the violation of these inequalities. Since the number of inequalities (of possible values of $\mathbf{n}$ ) is extremely large, we consider only values of $\mathbf{n}$ in a subset $C_{i t}$ of the set of feasible networks $A_{i t}$. We describe below the subsets $C_{i t}$. The estimator of $\boldsymbol{\theta}^{0} / \sigma_{\varepsilon}$ is defined as the value $\hat{\theta}_{M I E}$ that minimizes the following penalty function:

$$
Q(\boldsymbol{\theta})=\sum_{\mathbf{n} \in C_{i t}} \max \left\{\sum_{i=1}^{I_{t}} \sum_{t=1}^{T} \mathbf{Z}_{i t}\left[\widetilde{W}_{i t}(\mathbf{n}) \boldsymbol{\theta}+\gamma-\ln \hat{P}\left(\mathbf{n}_{i t} \mid \mathbf{X}_{t}\right)\right] ; 0\right\}^{2},
$$

where $\hat{P}\left(\mathbf{n}_{i t} \mid \mathbf{X}_{t}\right)$ is a nonparametric estimator of $P_{i}^{0}\left(n_{i t} \mid X_{t}\right)$.

The selection of the sets $C_{i t}$ of alternative choices is important for a precise estimation (and for the point identification) of all the parameters. The selection of these sets should imply enough 
variation with respect to $\mathbf{n}$ for every component of the vector $\widetilde{W}_{i t}(\mathbf{n})$. That is, the set $C_{i t}$ should contain choice alternatives for which the vector $\widetilde{W}_{i t}(\mathbf{n})$ is close to zero, but it should contain also choice alternatives for which each element of this vector is large enough. At the same time, for computational reasons, the number of elements in $C_{i t}$ should be orders of magnitude smaller than the number of elements in $A_{i t}$. For every observation $(i, t)$ in our sample, the set $C_{i t}$ contains the following branch networks for bank $i$ : (a) the actual choice, $\mathbf{n}_{i t}$; (b) opening (closing) up to five branches in headquarters-county (HQs) (up to 10 choice alternatives); (c) merged with the largest, or second largest, or third largest bank (in terms of number of branches) in HQs (up to 3 alternatives); (d) same as (b) and (c) but in county closest to HQs, and in county with the highest expected return, in county with the lowest risk, and in county with the lowest correlation, within the HQs state (up to 52 alternatives); (e) same as (b), (c), and (d) but for counties in states that share a border with the HQs state (up to 65 alternatives); and (f) same as (b), (c), and (d) but for counties in states that do not share a border with the HQs state (up to 65 alternatives). Each subset $C_{i t}$ contains a maximum of 196 choice alternatives, but in most of the cases the number of choice alternatives is around one hundred.

\subsection{Results}

Table 9 presents our estimates of bank preferences. The estimate of parameter $\bar{\rho}$ that measures banks' concerns for deposits risk is statistically and economically significant. Each percentage point of probability of insolvency is equivalent to an ad valorem tax on deposits of $10.4 \%$. The estimates of the parameters related to fixed operating cost show significant diseconomies of scale and economies of density. The cost of the first branch is $\$ 2.4$ millions, and the cost per branch increases with the number of branches: the cost per branch of a network with 10 branches is $\$ 3.5 M$, i.e., $\$ 2.4 M+10 * \$ 0.11 M$. We also find evidence of significant economies of density. The operating cost increases with the average distance of the branch network to the county with bank's headquarters. Every 100 miles of average distance to the headquarters implies an increase in the cost-per-branch of $\$ 178,000$. According to these estimates, for a branch network with 10 branches, the total fixed cost is $\$ 37 M$ if the average distance is 100 miles, and this cost increases to $\$ 44 M$ if the average distance is 500 miles.

The estimated costs of denovo branching and merging are sizeable. There are significant differences in these costs if the expansion is within the same state or to another state. The cost of a new branch is $\$ 1.5 M$ within the state, and it increases to $\$ 3.2 M$ is the new branch is open in a state different from the bank headquarters. The estimated merging cost per acquired branch is smaller than the cost of denovo branching especially for out of state expansions. We also find that merging costs per acquired branch are larger for small banks, defined as banks with less than 3 branches.

Summarizing, our estimates of bank preferences show that deposits risk has an important neg- 
ative effect on the value of a bank. However, this concern for risk diversification has been counterbalanced by economies of density and costs of expansion out state either through denovo branching or through mergers.

\section{Conclusion}

Our findings suggest that RN has substantially expanded the possibilities for geographic diversification of deposits risk for banks from small and homogeneous states. However, banks have not taken advantage of these opportunities such that only a small amount of the reduction in geographic risk since 1994 can be attributed to RN. Our estimates of bank preferences show that deposits risk has an important negative effect on the value of a bank, but that this concern for risk has been counterbalanced by concerns over economies of density and merging costs.

The fact that US banks remained geographically non-diversified more than a decade after the enactment of RN had important ramifications during the financial crisis of 2007-2008. Specifically, during the crisis bank failures were to a large extent concentrated in particular geographic locations. For instance 79 of 440 bank failures between the beginning of 2007 and 2012 occurred in Georgia. One reason for this is that banks in Georgia were, despite the opportunities afforded by RN, by and large quite small, and so their interests remained very local. Since the residential crisis hit Georgia particularly hard, its non-diversified banks suffered.

A clear implication of our analysis is that simply granting banks the right to expand across state lines, does not necessarily mean that they will act to lower their overall levels of geographic risk. Because of economies of density and merger costs, some banks are reluctant to expand far away from their headquarters. This is what we find in our estimation in Section 5. Moreover, even if banks reduce their geographic risk, as pointed out in earlier studies, they may take on more overall risk. Together, these findings suggest that the policy has not achieved its stated objective.

In order to encourage banks to diversify in such a way as to lower geographic risk, in addition to allowing across-state expansion, policy makers will have to find ways to reduce merger costs and make expansion more attractive. Some of this will happen naturally as a result of technological improvements. With the rise of internet-banking, the importance of the branch network will diminish, as will the need for branches to be in close proximity to headquarters.

Of course, ever since the financial crisis, policy makers may be less inclined towards the idea of encouraging greater expansion and more concentration in the banking industry. To avoid systemic risk, many have proposed shrinking too-big-to-fail institutions through divestiture. 


\section{APPENDIX A: Branch creation through mergers and denovo branches.}

Let $n_{\text {imt }}$ be the number of branches of bank $i$ in county $m$ at year $t$. And let $\Delta n_{\text {imt }}$ be the net change in the number of branches between years $t-1$ and $t$, i.e., $\Delta n_{i m t} \equiv n_{i m t}-n_{i m t-1}$. We can represent this net change as the sum of two components: $\Delta n_{i m t}=\Delta n_{i m t}^{M}+\Delta n_{i m t}^{D}$, where $\Delta n_{i m t}^{M}$ is the net change due to a merger or acquisition, and $\Delta n_{i m t}^{D}$ is the net change due to denovo openings or closings of branches. If bank $i$ has not acquired during year $t$ any of the banks with branches in market $m$ at $t-1$, then it is clear that the total net change $\Delta n_{\text {imt }}$ should be attributed to denovo branching, i.e., $\Delta n_{i m t}=\Delta n_{i m t}^{D}$. Otherwise, if during year $t$ bank $i$ has acquired other bank(s) with branches in county $m$, we assume that there has been first a merger and then a decision of opening or closing branches. According to this assumption, $\Delta n_{i m t}^{M}$ is equal to the total number of branches that the acquired bank (or banks) had in county $m$ at year $t-1$, and $\Delta n_{i m t}^{D}$ is constructed as the residual change $\Delta n_{i m t}^{D}=\Delta n_{i m t}-\Delta n_{i m t}^{M}$.

\section{APPENDIX B: Estimation of Factor Model}

The vector of factors $\mathbf{f}_{t}$ can be observable to the researcher or not. We have estimated both observable and unobservable factor models for our data, and we have obtained very similar results. Here we describe the estimation of the factor model with unobservable factors. ${ }^{23}$ Combining equation (5) with our specification of functions $\alpha_{m}\left(\mathbf{X}_{t}\right)$ and $\beta_{m}\left(\mathbf{X}_{t}\right)$, we can represent the factor model as $\ln \left(d_{m t}\right)=\alpha_{m}^{(0)}+\mathbf{X}_{m t}\left[\boldsymbol{\alpha}^{(1)}+\mathbf{B} \mathbf{f}_{t}\right]+u_{m t}=\alpha_{m}^{(0)}+\mathbf{X}_{m t} \gamma_{t}+u_{m t}$, where $\gamma_{t} \equiv \boldsymbol{\alpha}^{(1)}+\mathbf{B} \mathbf{f}_{t}$ that is a $K \times 1$ vector. Using $T$ time-dummy variables, $t d_{t}^{(1)}, \ldots, t d_{t}^{(T)}$, we can write the model as:

$$
\ln d_{m t}=\alpha_{m}^{(0)}+\left[\begin{array}{llll}
\mathbf{X}_{m t} * t d_{t}^{(1)}, & \mathbf{X}_{m t} * t d_{t}^{(2)}, \quad \ldots, & \mathbf{X}_{m t} * t d_{t}^{(T)}
\end{array}\right]\left[\begin{array}{c}
\gamma_{1} \\
\gamma_{2} \\
\vdots \\
\gamma_{T}
\end{array}\right]+u_{m t}
$$

where $\mathbf{X}_{m t}^{*}$ is the row vector $\mathbf{X}_{m t} *\left[t d_{t}^{(1)}, t d_{t}^{(2)}, \ldots, t d_{t}^{(T)}\right]$, and $\gamma$ is the $K T \times 1$ vector with the $\gamma_{t}$ 's. (Step 1) Estimation of vectors of expected 'returns', $\left\{\boldsymbol{\mu}_{t}^{D}\right\}$. Equation (A.1) is a dynamic linear panel data with fixed effects $\alpha_{m}^{(0)}$, vector of regressors $\mathbf{X}_{m t}^{*}$, vector of parameters $\gamma$, and transitory shock $u_{m t}$. It is a dynamic model because the vector of regressors includes the lagged dependent variable $\ln \left(d_{m t-1}\right)$. We estimate the vector of parameters $\gamma$ in this model using two different estimators: a simple fixed-effects (within-groups) estimator, and the Arellano and Bond (1991) GMM estimator. In dynamic panel data models, it is well-known that the fixed effects estimator is consistent only as $M$ and $T$ go to infinity, but not when $T$ is small. Since the number of periods in our panel is relatively large $(T=13)$, it is arguable that the bias of the fixed effects estimator might not be too large. Arellano-Bond estimator is consistent when $T$ is small, but it may suffer from a weak instruments problem when the coefficient of the lagged dependent variable, $\ln \left(d_{m t-1}\right)$,

\footnotetext{
${ }^{23}$ In the model with observable factors, we have used six factors: growth rate of deposits per branch at the national level, growth rate of number of branches at the national level, growth rate of national income, inflation rate, effective Federal Funds rate of interest (annual average), and standard deviation of the weekly average of the effective Federal Funds rate of interest.
} 
is close to one. As a robustness test, we have estimated $\gamma$ using the two estimators, and we have obtained similar results. Given our estimate of the vector $\gamma$, we estimate the fixed effect $\alpha_{m}^{(0)}$ as $\hat{\alpha}_{m}^{(0)}=T^{-1} \sum_{t=1}^{T}\left(\ln d_{m t}-X_{m t}^{*} \widehat{\gamma}\right)$. Then, taking into account that $\gamma_{t} \equiv \boldsymbol{\alpha}^{(1)}+\mathbf{B} \mathbf{f}_{t}$ and $\mathbb{E}\left(\mathbf{B} \mathbf{f}_{t}\right)=0$, our estimator of the vector $\boldsymbol{\alpha}^{(1)}$ is $\widehat{\boldsymbol{\alpha}}^{(1)}=T^{-1} \sum_{t=1}^{T} \widehat{\gamma}_{t}$. And given $\widehat{\boldsymbol{\alpha}}^{(0)}$ and $\widehat{\boldsymbol{\alpha}}^{(1)}$, the estimated vector of expected 'returns' is $\widehat{\boldsymbol{\mu}}_{t}^{D}=\widehat{\boldsymbol{\alpha}}^{(0)}+\mathbf{X}_{t} \widehat{\boldsymbol{\alpha}}^{(1)}$.

(Step 2) Estimation of variance-covariance matrices of risks, $\left\{\boldsymbol{\Omega}_{t}^{D}\right\}$. The estimation of matrix $\boldsymbol{\Omega}_{t}^{D}$ has three different parts: (a) estimation of the $K \times K$ matrix $\left(\mathbf{B} \boldsymbol{\Sigma}_{\mathbf{f}} \mathbf{B}^{\prime}\right)$ that accounts for the contribution of 'systematic' risk to the variance $\boldsymbol{\Omega}_{t}^{D}$; (b) estimation of the vector of parameters $\boldsymbol{\rho}$ that accounts for additional spatial correlation in local market shocks; and (c) estimation of the parameters $\boldsymbol{\delta}$ that account for heteroskedasticity in variance of diversifiable risk.

(a) Estimation of matrix $\mathbf{B} \boldsymbol{\Sigma}_{\mathbf{f}} \mathbf{B}^{\prime}$. Define the $K \times 1$ vector $\mathbf{v}_{t} \equiv \mathbf{B} f_{t}$ associated with the systematic part of the risk. By definition, we have that $\mathbb{E}\left(\mathbf{v}_{t} \mathbf{v}_{t}^{\prime}\right)=\mathbf{B} \boldsymbol{\Sigma}_{\mathbf{f}} \mathbf{B}^{\prime}$. Also, we have that $\boldsymbol{\gamma}_{t} \equiv \boldsymbol{\alpha}^{(1)}+\mathbf{v}_{t}$, and therefore, $\mathbb{E}\left(\left[\boldsymbol{\gamma}_{t}-\boldsymbol{\alpha}^{(1)}\right]\left[\boldsymbol{\gamma}_{t}-\boldsymbol{\alpha}^{(1)}\right]^{\prime}\right)=\mathbf{B} \boldsymbol{\Sigma}_{\mathbf{f}} \mathbf{B}^{\prime}$. Given our estimators $\widehat{\gamma}_{t}$ and $\widehat{\boldsymbol{\alpha}}^{(1)}=T^{-1} \sum_{t=1}^{T} \widehat{\gamma}_{t}$, we have that $T^{-1} \sum_{t=1}^{T}\left[\widehat{\gamma}_{t}-\widehat{\boldsymbol{\alpha}}^{(1)}\right]\left[\widehat{\boldsymbol{\gamma}}_{t}-\widehat{\boldsymbol{\alpha}}^{(1)}\right]^{\prime}$ is a consistent estimator of matrix $\mathbf{B} \boldsymbol{\Sigma}_{\mathbf{f}} \mathbf{B}^{\prime}$.

(b) Estimation of parameters $\boldsymbol{\rho}$ in the spatial stochastic process of the idiosyncratic shock. Let $\widehat{u}_{m t}$ be the residual for $u_{m t}$ from the regression in Step 1, i.e., $\widehat{u}_{m t}=\ln d_{m t}-\mathbf{X}_{m t}^{*} \widehat{\gamma}-\widehat{\alpha}_{m}^{(0)}$. Given these residuals, we construct the values $\widetilde{\widehat{u}}_{m t}^{(1)}, \widetilde{\widehat{u}}_{m t}^{(2)}, \ldots, \widetilde{\widehat{u}}_{m t}^{(S)}$ for the $S$ bands in the spatial autoregressive process of $u_{m t}$. Then, we run an OLS regression of $\widehat{u}_{m t}$ on $\widetilde{\widehat{u}}_{m t}^{(1)}, \widetilde{\widehat{u}}_{m t}^{(2)}$, ..., $\widetilde{\widehat{u}}_{m t}^{(S)}$ to obtain consistent estimates of the parameters $\rho_{1}, \rho_{2}$, and $\rho_{S}$.

(c) Estimation of parameters variance of diversifiable risk. Let $\widehat{e}_{m t}$ be the OLS residuals from the estimation of the spatial process, i.e., $\widehat{e}_{m t}=\widehat{u}_{m t}-\widehat{\rho}_{1} \widetilde{\widehat{u}}_{m t}^{(1)}-\ldots-\widehat{\rho}_{S} \widetilde{\widehat{u}}_{m t}^{(S)}$. We run an OLS regression for $\ln \left(\left|\widehat{e}_{m t}\right|\right)$ on $\mathbf{X}_{m t}$ and county-fixed effects (fixed effects regression). This regression gives us consistent estimates of the parameters $\delta_{m}^{(0)}$ and $\boldsymbol{\delta}^{(1)}$.

Combining steps (a), (b), and (c), we construct the following estimator of matrix $\boldsymbol{\Omega}_{m t}^{D}$ :

$$
\widehat{\boldsymbol{\Omega}_{m t}^{D}}=\mathbf{X}_{m t}\left(\frac{1}{T} \sum_{t=1}^{T}\left[\widehat{\gamma}_{t}-\widehat{\boldsymbol{\alpha}}^{(1)}\right]\left[\widehat{\gamma}_{t}-\widehat{\boldsymbol{\alpha}}^{(1)}\right]^{\prime}\right) \mathbf{X}_{m t}^{\prime}+(I-\widehat{\boldsymbol{\rho}} \mathbf{W})^{-1} \mathbf{D}\left(\widehat{\boldsymbol{\delta}}, \mathbf{X}_{t}\right)\left(I-(\widehat{\boldsymbol{\rho}} \mathbf{W})^{\prime}\right)^{-1}
$$

\section{APPENDIX C: Efficient Risk-Return Frontiers}

The standard (Markovitz) efficient Risk-Return frontier is a real-valued function $f($.$) that relates$ the expected return of a portfolio with the risk of the portfolio, i.e., $R=f(S)$, such that $f(S)$ is the maximum expected return of a portfolio with risk $S$. Let $w_{m}$ be the share of asset $m$ in the portfolio. When all the assets are perfectly divisible and the investor can be short of any asset, we have that the efficient frontier $f(S)$ is the maximum (in $w_{1}, w_{2}, \ldots, w_{M}$ ) of $\sum_{m=1}^{M} w_{m} \mu_{m}^{*}$ subject to $\sum_{m=1}^{M} w_{m}=1$, and $\sum_{m=1}^{M} \sum_{m^{\prime}=1}^{M} w_{m} w_{m^{\prime}} \sigma_{m m^{\prime}}^{*}=S^{2}$. However, the portfolio choice problem and the efficient frontiers that we consider in this paper are not standard. First, in our case the unit of each asset is a branch that is discrete and indivisible, i.e., the weights $w_{m}$ are not continuous variables. Second, banks cannot be short on branches in any local market such that the weights $w_{m}$ cannot take negative values. Third, before Riegle Neal Act, banks in different states had different sets of assets/markets where they could invest. Finally, we also take into account that 
most banks have a "home bias" to invest in the local market where they originated and have their headquarters. Our construction of efficient portfolio frontiers takes into account these important aspects that affect the branch portfolio of a bank. Given a set of states $G$, a "home" local market $h$, and a maximum number of branches $\operatorname{maxn}$, let $A(G, h, \operatorname{maxn})$ represent the set of possible branch networks (portfolios) that satisfy the following conditions: (i) all the branches are located in counties that belong to states in set $G$; (ii) there is at least one branch in home county $h$; and (iii) the total number of branches in the network is lower or equal than maxn. Given the feasible set $A(G, h, \operatorname{maxn})$, the efficient frontier is defined as the set of risk-return pairs $(S, R)$ such that $R=f(S \mid G, h, \max n)$ and:

$$
\begin{aligned}
f(S \mid G, h, \max n)= & \max _{\left\{n_{1}, n_{2}, \ldots, n_{M}\right\}} \sum_{m=1}^{M}\left(\frac{n_{m}}{\operatorname{maxn}}\right) \mu_{m}^{*} \\
& \text { subject to: } n_{m}=0 \text { if } m \notin G ; n_{h}>0 ; \sum_{m=1}^{M} n_{m} \leq \operatorname{maxn} ; \\
& \text { and } \sum_{m=1}^{M} \sum_{m^{\prime}=1}^{M}\left(\frac{n_{i m}}{\operatorname{maxn}}\right)\left(\frac{n_{i m^{\prime}}}{\operatorname{maxn}}\right) \sigma_{m m^{\prime}}^{*}=S^{2}
\end{aligned}
$$

\section{APPENDIX D: Decomposition of the change in the empirical distributions of banks' expected deposits and risk.}

Every bank that we observe in our sample is identified by a Certificate Number $(C E R T)$. After a merger, the CERT of only one of the merging banks survives. The certificate numbers of the other merging banks are cancelled and never used again. For every bank that we observe in our sample (or more precisely, for every CERT), we can define the following dummy or indicator variables: (1) $A C T$ is the dummy variable that indicates that the CERT is active at year 2006; (2) ACTMERG is equal to 1 iff the CERT is not active in 2006 but this CERT was involved in one or several mergers between 1995 and 2006, and in 2006 there is a surviving bank that comes from these mergers; (3) MERG is the dummy variable indicating that the CERT has been involved in a merger between 1995 and 2006; and (4) MERGOUT is the dummy variable indicating that the CERT has been involved in a merger between banks with different home states. For the construction of $\left\{I_{06}^{I N}, \mathbf{n}_{06}^{I N}\right\}$, we describe a bank's history during 1995-2005 using the dummy variables ACT, ACTMERG, MERG, and MERGOUT. Table Appendix D presents the eight possible values of these variables. ${ }^{24}$ Histories type (A), (B) and (C) represent bank failures or exits: (A) is exit without mergers, (B) is exit with within-state mergers, and $(\mathrm{C})$ represents exits with multi-state mergers. Banks with either of these histories are not included in the counterfactuals $I_{06}^{I N}$. Histories type (D), (E) and (F) correspond to banks with CERT that is active in 2006. This bank may have not being involved in any merge (i.e., type (D)), or in within-state merger(s) only (i.e., type (E)), or in multi-state merger(s) (i.e., type (F)). Finally, histories $(\mathrm{G})$ and $(\mathrm{H})$ represent banks with ACTMERG equal to 1: CERT is not active in 2006 but this CERT was involved in a merger between 1995 and 2006, and the surviving CERT from that merger is active in 2006. We have two types in this category: within-state merger(s) only (i.e., type $(\mathrm{G})$ ), or in multi-state merger(s) (i.e., type $(\mathrm{H})$ ).

\footnotetext{
${ }^{24}$ By definition, not all the combinations of $A C T, A C T M E R G, M E R G$, and $M E R G O U T$ are possible.
} 


\begin{tabular}{|c|c|c|c|c|c|c|c|c|}
\hline & \multicolumn{8}{|c|}{$\begin{array}{l}\text { Table: Appendix D } \\
\text { rfactual Distributions in Figures } 11 \text { and } 12\end{array}$} \\
\hline & \multicolumn{4}{|c|}{ Bank History 1995-2006 } & \multirow{2}{*}{$\begin{array}{c}\text { \# banks } \\
(\%)\end{array}$} & \multicolumn{3}{|c|}{ Counterfactual Distribution $f\left(\Omega_{06}, I_{06}^{I N}, n_{06}^{I N}\right)$} \\
\hline & $\mathrm{ACT}$ & ACTMERG & MERG & MERGOUT & & Set $I_{06}$ & Set $I_{06}^{I N}$ & Branch network $n_{06}^{I N}$ \\
\hline (A) & 0 & 0 & 0 & 0 & $\begin{array}{c}172 \\
(1.2 \%)\end{array}$ & Not Included & Not Included & None. \\
\hline (B) & 0 & 0 & 1 & 0 & $\begin{array}{c}11 \\
(0.1 \%)\end{array}$ & Not Included & Not Included & None. \\
\hline (C) & 0 & 0 & 1 & 1 & $\begin{array}{c}8 \\
(0.1 \%)\end{array}$ & Not Included & Not Included & None. \\
\hline (D) & 1 & 0 & 0 & 0 & $\begin{array}{c}7,259 \\
(51.3 \%)\end{array}$ & Included & Included & $\begin{array}{l}\text { Actual network in } 2006 \\
\text { but "closing" branches } \\
\text { that come from denovo } \\
\text { branching outside home state. }\end{array}$ \\
\hline$(\mathrm{E})$ & 1 & 0 & 1 & 0 & $\begin{array}{c}1,135 \\
(8.0 \%)\end{array}$ & Included & Included & $\begin{array}{l}\text { Actual network in } 2006 \\
\text { but "closing" branches } \\
\text { that come from denovo } \\
\text { branching outside home state. }\end{array}$ \\
\hline$(\mathrm{F})$ & 1 & 0 & 1 & 1 & $\begin{array}{c}324 \\
(2.3 \%)\end{array}$ & Included & Included & $\begin{array}{l}\text { Actual network in } 2006 \\
\text { but "closing" branches } \\
\text { outside the home state that } \\
\text { come from denovo or mergers. }\end{array}$ \\
\hline (G) & 0 & 1 & 1 & 0 & $\begin{array}{c}3,897 \\
(27.5 \%)\end{array}$ & Not Included & Not Included & $\begin{array}{l}\text { None. Including these banks } \\
\text { is redundant with type (E). }\end{array}$ \\
\hline \multirow[t]{2}{*}{$(\mathrm{H})$} & 0 & 1 & 1 & 1 & $\begin{array}{l}1,339 \\
(9.5 \%)\end{array}$ & Not Included & Included & $\begin{array}{l}\text { Actual network in } 2006 \text { of } \\
\text { bank with surviving CERT but } \\
\text { including branches only at home } \\
\text { state of CERT included here. }\end{array}$ \\
\hline & & & & Total & $\begin{array}{l}14,145 \\
(100 \%)\end{array}$ & & & \\
\hline
\end{tabular}




\section{References}

[1] Ackerberg, D., and G. Gowrisankaran (2006): "Quantifying Equilibrium Network Externalities in the ACH Banking Industry," RAND Journal of Economics, 37, 738-61.

[2] Akhigbe, A. and A. Whyte (2003): "Changes in Market Assessments of Bank Risk Following the Riegel-Neal Act of 1994," Journal of Banking and Finance, 27, 87-102.

[3] Akkus, O., J. Cookson, and A. Hortacsu (2012): "The Determinants of Bank Mergers: A Revealed Preference Analysis," manuscript. University of Chicago.

[4] Alhadeff, A. (1962): "A Reconsideration of Restrictions on Bank Entry," Quarterly Journal of Economics. Vol. 77.Vol. 76, No. 2 (May, 1962), pp. 246-263

[5] Arellano, M. anf S. Bond (1991): "Some Tests of Specification for Panel Data: Monte Carlo Evidence and an Application to Employment Equations," Review of Economic Studies, 58(2), 277-297.

[6] Brevoort, K., and J. Wolken (2009): "Does Distance Matter in Banking?" chapter 3 in book "The Changing Geography of Banking and Finance," P. Alessandrini, M. Fratianni, and A. Zazzaro, Alberto (eds.) Springer.

[7] Brewer, E. and Jackson, W.E and Jagtiani, J.A (2000): "Impact of Independent Directors and the Regulatory Environment on Bank Merger Prices: Evidence from Takeover Activity in the 1990s," Federal Reserve Bank of Chicago, WP-00-31.

[8] Calomiris, C. (2000): "U.S. Bank Deregulation in Historical Perspective," Cambridge University Press. Cambridge, UK.

[9] Carlson, M. (2004): "Are Branch Banks Better Survivors? Evidence From the Depression Era," Economic Inquiry, 42, 111-126.

[10] Chernozukov, Hong, and Tamer (2007): "Estimation and Inference on Identified Parameter Sets," Econometrica.

[11] Cohen, A., and M. Mazzeo (2007): "Market Structure and Competition among Retail Depository Institutions," Review of Economics and Statistics, 89, 60-74.

[12] Cohen, A., and M. Mazzeo (2010): "Investment Strategies and Market Structure: An Empirical Analysis of Bank Branching Decisions," Journal of Financial Services Research 38:1, 1-21.

[13] Corbae, D., and P. D'Erasmo (2011): "A Quantitative Model of Banking Industry Dynamics," manuscript. University of Maryland at College Park.

[14] Davis, S. and J. Haltiwanger (1992):"Gross Job Creation, Gross Job Destruction, and Employment Reallocation," Quarterly Journal of Economics, 107(3), 819-863.

[15] Demsetz, R. and P. Strahan (1997): "Diversification, Size, and Risk at U.S. Bank Holding Companies," Journal of Money, Credit, and Banking, 29, 300-313.

[16] Deng, and E. Elyasiani (2008): "Geographic Diversification and BHC Return and Risk Performance," Journal of Money, Credit and Banking, 40, 1217-1238.

[17] Dick, A. (2006): "Nationwide Branching and Its Impact on Market Structure, Quality, and Bank Performance," Journal of Business, 79(2).

[18] Economides, N., G. Hubbard, and D. Palia (1996): "The Political Economy of Branching Restrictions and Deposit Insurance: A Model of Monopolistic Competition among Small and Large Banks," Journal of Law and Economics, 39(2), 667-704

[19] Emmons, W.R. and Gilbert, R.A and Yeager, T.J. (2002): "Scale Economies and Geographic Diversification as Forces Driving Community Bank Mergers," Federal Reserve Bank of St. Louis, WP-2002-02. 
[20] Fama, E. and K. French (1992): "The Cross-Section of Expected Stock Returns," Journal of Finance, 47, 427-465.

[21] Fama, E. and K. French (1993): "Common Risk Factors in the Returns on Stocks and Bonds," Journal of Financial Economics, 33, 3-56.

[22] Felici, Roberto, and Pagnini, Marcello (2008): "Distance, Bank Heterogeneity and Entry in Local Banking Markets," The Journal of Industrial Economics, 56, 500-534.

[23] Gowrisankaran, G., and J. Krainer (2011): "Entry and Pricing in a Differentiated Products Industry: Evidence from the ATM Market," RAND Journal of Economics, 42, 1-22.

[24] Hart, O. and D. Jaffe (1974): "On the Application of Portfolio Theory to Depository Financial Intermediaries," The Review of Economic Studies, 41, 129-147.

[25] Ho, K. and J. Ishii (2010): "Location and Competition in Retail Banking," International Journal of Industrial Organization, 29(5), 537-546.

[26] Holmes, T (2011): "The Diffusion of Wal-Mart and Economies of Density," Econometrica, $79(1), 253-302$.

[27] Hughes, J.P. and Lang, W. and Mester, L.J. and Moon, C.G. (1996): "Efficient Banking Under Interstate Branching," Journal of Money, Credit, and Banking, 28, 1045-1071

[28] Jia, P. (2008): "What Happens When Wal-Mart Comes to Town: An Empirical Analysis of the Discount Retail Industry," Econometrica, 76(6), 1263-1316.

[29] Kane, Edward (1996): "De Jure Interstate Banking: Why Only Now?" Journal of Money, Credit and Banking, 28(2), 141-161.

[30] Kroszner, R., and P. Strahan (1999): "What Drives Deregulation? Economics and Politics of the Relaxation of Bank Branching Restrictions," The Quarterly Journal of Economics, 114(4), $1437-1467$.

[31] Levonian, M.E. (1994): "Interstate Banking and Risk," Weekly Letter, Federal Reserve Bank of San Francisco, 94-26, 1-2.

[32] Liang, J.N. and Rhoades, S.A. (1999): "Asset Diversification, Firm Risk, adn Risk-Based Capital Requirements in Banking," Review of Industrial Organization, 6, 49-59.

[33] Pakes, A. (2010): "Alternative Models for Moment Inequalities," Econometrica, 78, 1783-1822.

[34] Pakes, A., J. Porter, K. Ho, and J. Ishii (2006): "Moment Inequalities and Their Application," manuscript. Department of Economics. Harvard University.

[35] Rice, Tara and Erin Davis (2007): "The branch banking boom in Illinois: A byproduct of restrictive branching laws," Chicago Fed Letter, number 238.

[36] Rose, P.S. (1995): "Diversification and Interstate Banking," The New Tool Set: Assessing Innovations in Banking, 31st Annual Conference on Bank Structure and Competition, May 1995, 296-313.

[37] Ross, S. (1976): "The Arbitrage Theory of Capital Asset Pricing," Journal of Economic Theory, 13, 341-360.

[38] Schmid, M. and Walter, I. (2008): "Geographic Diversification and Firm Value in the Financial Services Industry, " working paper.

[39] Wang, H. (2009): "Consumer Valuation of Retail Networks: Evidence from the Banking Industry," manuscript. University of Toronto.

[40] White, E.N. (1984): "A Reinterpretation of the Banking Crisis of 1930," The Journal of Economic History, 44, 119-138. 


\begin{tabular}{|c|c|c|c|c|c|}
\hline \multicolumn{6}{|c|}{ TABLE 1. Descriptive Statistics } \\
\hline Statistics & 1994 & 1997 & 2000 & 2003 & 2006 \\
\hline \multicolumn{6}{|l|}{ Banks: } \\
\hline Number of banks & 12,976 & 11,164 & 10,098 & 9,238 & 8,749 \\
\hline Change in number of banks during last 3 years & & -1812 & -1066 & -860 & -489 \\
\hline Openings of new banks during last 3 years & & 402 & 735 & 391 & 477 \\
\hline Closings of banks during last 3 years due to mergers & & 2154 & 1761 & 1187 & 937 \\
\hline Closings of banks during last 3 years due to failures & & 60 & 40 & 64 & 29 \\
\hline \multicolumn{6}{|l|}{ Branches: } \\
\hline Number of branches & 80,795 & 81,553 & 84,909 & 87,183 & 94,123 \\
\hline Average number of branches per bank & 6.2 & 7.3 & 8.4 & 9.4 & 10.8 \\
\hline Median number of branches per bank & 2 & 2 & 2 & 3 & 3 \\
\hline$\%$ denovo branches from banks with HQs in other state & 8.9 & 15.8 & 21.6 & 30.9 & 32.7 \\
\hline \multicolumn{6}{|l|}{ Branch creation accounted by mergers (\%) } \\
\hline Overall sample & 64.8 & 68.7 & 57.5 & 51.0 & 53.5 \\
\hline In markets within the same state as bank HQs & 60.9 & 49.7 & 43.1 & 33.3 & 32.8 \\
\hline In markets in different state than bank HQs & 82.7 & 91.0 & 75.7 & 65.2 & 67.9 \\
\hline
\end{tabular}

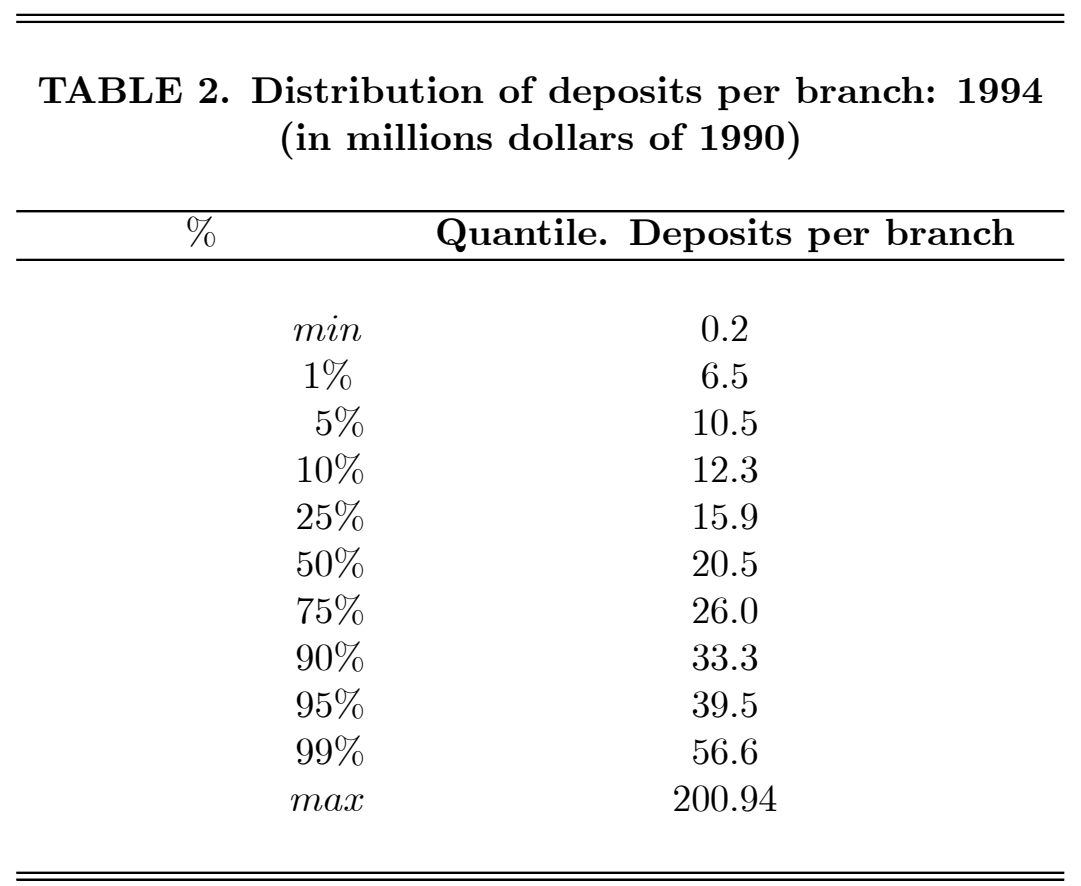


TABLE 3. Estimation of Factor Model for log-deposits-per-branch (unobserved factors)

\begin{tabular}{|c|c|c|c|}
\hline \multicolumn{4}{|c|}{ Panel (3a): Arellano-Bond estimation of parameters in Mean $\boldsymbol{\mu}^{D}$} \\
\hline \multicolumn{2}{|c|}{$\boldsymbol{\alpha}^{(1)}$ Parameters } & \multicolumn{2}{|c|}{$\boldsymbol{\alpha}_{m}^{(0)}$ Fixed effects parameters } \\
\hline Variable & Estimate (s.e.) & Probability & Quantile \\
\hline Lagged log deposits & $0.7383(0.0067)^{*}$ & minimun & -1.449 \\
\hline Lagged log \# branches & $0.0343(0.0071)^{*}$ & Quantile $5 \%$ & -1.284 \\
\hline $\log$ Population & $0.0990(0.0141)^{*}$ & Quantile $25 \%$ & -1.134 \\
\hline $\log$ Income & $0.0734(0.0140)^{*}$ & Quantile $50 \%$ & -1.042 \\
\hline Employ. share Management & $0.1875(0.1564)$ & Quantile $75 \%$ & -0.978 \\
\hline Employ. share Real Estate & $0.1642(0.1690)$ & Quantile $95 \%$ & -0.792 \\
\hline Employ. share IT & $0.1332(0.1485)$ & maximum & -0.269 \\
\hline Employ. share Retail & $0.1014(0.1534)$ & & \\
\hline \multicolumn{4}{|c|}{ 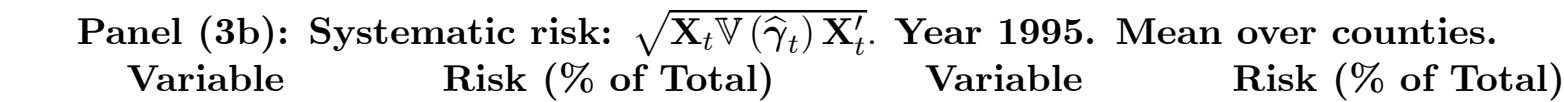 } \\
\hline Total & $0.5829(100 \%)$ & Lagged log deposits & $0.0499(8.5 \%)$ \\
\hline log Income & $0.2751(47.2 \%)$ & Lagged log \# branches & $0.0236(4.0 \%)$ \\
\hline $\log$ Population & $0.0957(16.4 \%)$ & & \\
\hline Industry Employ. Shares & $0.0836(14.3 \%)$ & & \\
\hline \multicolumn{4}{|c|}{ Panel (3c): Spatial Autoreggressive Process of $u_{m t}$} \\
\hline Parameter & Estimate (s.e.) & Parameter & Estimate (s.e.) \\
\hline$\rho(<200$ miles $)$ & $0.3573(0.0229)$ & $\rho(400$ to 1,000 miles $)$ & $0.1115(0.0544)$ \\
\hline$\rho(200$ to 400 miles $)$ & $0.2699(0.0321)$ & $\rho(>1,000$ miles $)$ & $-0.1510 \quad(0.2883)$ \\
\hline
\end{tabular}

Panel (3d): Parameters in variance of Diversifiable risk

\begin{tabular}{rrr|cc}
\multicolumn{2}{c|}{$\boldsymbol{\delta}^{(1)}$ Parameters } & \multicolumn{2}{c}{$\boldsymbol{\delta}_{m}^{(0)}$ Fixed effects parameters } \\
\hline \multicolumn{2}{c|}{ Estimate (s.e.) } & \multicolumn{2}{c}{ Probability } & Quantile \\
\hline Variable & & minimun & -10.150 \\
Lagged log deposits & $-0.2102(0.1137)$ & Quantile 5\% & -8.327 \\
Lagged $\log \#$ branches & $-0.2169(0.1405)$ & Quantile 25\% & -7.486 \\
$\log$ Population & $0.2273(0.2823)$ & Quantile 50\% & -6.951 \\
$\log$ Income & 0.0275 & $(0.0934)$ & Quantile $75 \%$ & -6.428 \\
& & Quantile 95\% & -5.692 \\
& & maximum & -3.963 \\
\hline \hline
\end{tabular}


TABLE 4. Change in Efficient Frontiers after Riegle-Neal: 1995-2006

$\%$ change in Maximum Return-to-Risk ratio (Max RR) and Minimum Risk (Min Risk)

States sorted by Max RR in 1995

\begin{tabular}{|c|c|c|c|c|c|c|c|c|c|}
\hline \multirow[b]{3}{*}{ State (\# counties) } & \multicolumn{2}{|c|}{ Year 1995} & \multicolumn{2}{|c|}{$\%$ change 95 to 06} & \multirow[b]{3}{*}{ State (\# counties) } & \multicolumn{2}{|c|}{ Year 1995} & \multicolumn{2}{|c|}{$\%$ change 95 to 06} \\
\hline & Max & Min & $\operatorname{Max}$ & Min & & $\operatorname{Max}$ & Min & $\operatorname{Max}$ & Min \\
\hline & $\mathrm{RR}$ & Risk & $\mathrm{RR}$ & Risk & & $\mathrm{RR}$ & Risk & $\mathrm{RR}$ & Risk \\
\hline Texas (248) & 805 & $0.40 \%$ & $42 \%$ & $-29 \%$ & Pennsylvania (67) & 452 & $0.69 \%$ & $153 \%$ & $-59 \%$ \\
\hline Missouri (115) & 668 & $0.45 \%$ & $71 \%$ & $-36 \%$ & Vermont (14) & 447 & $0.70 \%$ & $155 \%$ & $-59 \%$ \\
\hline Georgia (156) & 647 & $0.47 \%$ & $76 \%$ & $-39 \%$ & North Dakota (51) & 442 & $0.68 \%$ & $158 \%$ & $-58 \%$ \\
\hline N. Carolina (100) & 646 & $0.47 \%$ & $77 \%$ & $-39 \%$ & Michigan (82) & 415 & $0.69 \%$ & $175 \%$ & $-59 \%$ \\
\hline Louisiana (64) & 629 & $0.49 \%$ & $81 \%$ & $-41 \%$ & Montana (54) & 408 & $0.73 \%$ & $179 \%$ & $-61 \%$ \\
\hline Virginia (131) & 629 & $0.48 \%$ & $81 \%$ & $-40 \%$ & California (57) & 404 & $0.82 \%$ & $182 \%$ & $-65 \%$ \\
\hline Wisconsin $(71)$ & 625 & $0.48 \%$ & $82 \%$ & $-40 \%$ & New Hampshire (10) & 368 & $0.93 \%$ & $210 \%$ & $-69 \%$ \\
\hline Kentucky (120) & 620 & $0.51 \%$ & $84 \%$ & $-43 \%$ & New Mexico (31) & 350 & $0.87 \%$ & $226 \%$ & $-67 \%$ \\
\hline Illinois (102) & 593 & $0.53 \%$ & $92 \%$ & $-46 \%$ & Colorado (61) & 339 & $0.88 \%$ & $236 \%$ & $-68 \%$ \\
\hline Arkansas (75) & 584 & $0.52 \%$ & $95 \%$ & $-44 \%$ & Idaho $(42)$ & 320 & $0.90 \%$ & $257 \%$ & $-68 \%$ \\
\hline Oklahoma (77) & 583 & $0.53 \%$ & $96 \%$ & $-46 \%$ & Maine (16) & 317 & $0.91 \%$ & $260 \%$ & $-68 \%$ \\
\hline West Virginia (55) & 583 & $0.55 \%$ & $96 \%$ & $-48 \%$ & Alaska (19) & 314 & $0.97 \%$ & $263 \%$ & $-70 \%$ \\
\hline Alabama (67) & 582 & $0.54 \%$ & $96 \%$ & $-47 \%$ & Oregon $(36)$ & 307 & $0.98 \%$ & $271 \%$ & $-71 \%$ \\
\hline Mississippi (82) & 568 & $0.52 \%$ & $101 \%$ & $-45 \%$ & Wyoming (23) & 301 & $1.06 \%$ & $279 \%$ & $-73 \%$ \\
\hline Kansas (105) & 565 & $0.55 \%$ & $102 \%$ & $-48 \%$ & New Jersey (21) & 297 & $1.08 \%$ & $283 \%$ & $-73 \%$ \\
\hline Florida (66) & 562 & $0.56 \%$ & $103 \%$ & $-49 \%$ & Maryland (24) & 290 & $1.03 \%$ & $293 \%$ & $-72 \%$ \\
\hline Tennessee (95) & 518 & $0.60 \%$ & $120 \%$ & $-52 \%$ & Utah (28) & 286 & $0.99 \%$ & $299 \%$ & $-71 \%$ \\
\hline New York (62) & 509 & $0.64 \%$ & $124 \%$ & $-55 \%$ & Delaware (3) & 284 & $1.25 \%$ & $301 \%$ & $-77 \%$ \\
\hline South Dakota (64) & 498 & $0.60 \%$ & $129 \%$ & $-52 \%$ & Connecticut (8) & 277 & $1.16 \%$ & $313 \%$ & $-75 \%$ \\
\hline Nebraska (92) & 496 & $0.61 \%$ & $130 \%$ & $-53 \%$ & Arizona (15) & 274 & $1.18 \%$ & $316 \%$ & $-76 \%$ \\
\hline S. Carolina (46) & 485 & $0.62 \%$ & $135 \%$ & $-54 \%$ & Washington (39) & 267 & $1.10 \%$ & $327 \%$ & $-74 \%$ \\
\hline Indiana (92) & 482 & $0.64 \%$ & $137 \%$ & $-55 \%$ & Massachusetts (14) & 248 & $1.37 \%$ & $359 \%$ & $-79 \%$ \\
\hline Minnesota (87) & 479 & $0.62 \%$ & $138 \%$ & $-54 \%$ & Nevada (16) & 223 & $1.34 \%$ & $412 \%$ & $-79 \%$ \\
\hline Ohio (88) & 473 & $0.66 \%$ & $141 \%$ & $-57 \%$ & Rhode Island (5) & 219 & $1.65 \%$ & $421 \%$ & $-83 \%$ \\
\hline Iowa (99) & 465 & $0.66 \%$ & $146 \%$ & $-56 \%$ & Hawaii (4) & 118 & $3.12 \%$ & $864 \%$ & $-91 \%$ \\
\hline
\end{tabular}

Note: Columns "(06-95)/95 (\%)" report the percentage change between 1995 and 2006 in maximum possible Return

to Risk Ratio (MaxRR) and minimum possible risk (MinRisk) along the state efficient frontiers. 
TABLE 5. Feasible Minimum Risk for Small Banks before Riegle-Neal. Year 1995

States sorted by Maximum Return-to-Risk Ratio in the Efficient Frontier in 1995

\begin{tabular}{|c|c|c|c|c|c|c|c|c|c|}
\hline State (\# counties) & \multicolumn{4}{|c|}{ Minimum Risk with $\mathrm{n}$ branches (\%) } & State (\# counties) & $\begin{array}{l}\text { Minim } \\
\mathrm{n}=1\end{array}$ & \multicolumn{3}{|c|}{ Minimum Risk with $\mathrm{n}$ branches (\%) } \\
\hline Texas $(248)$ & 2.39 & 0.74 & 0.57 & 0.57 & Pennsylvania (67) & 1.97 & 0.87 & 0.77 & 0.77 \\
\hline Missouri (115) & 2.23 & 0.69 & 0.56 & 0.56 & Vermont (14) & 2.10 & 0.82 & 0.73 & 0.73 \\
\hline Georgia (156) & 2.64 & 0.75 & 0.58 & 0.58 & North Dakota (51) & 2.13 & 0.87 & 0.75 & 0.75 \\
\hline N. Carolina (100) & 2.15 & 0.69 & 0.55 & 0.55 & Michigan (82) & 2.40 & 0.91 & 0.78 & 0.78 \\
\hline Louisiana (64) & 2.39 & 0.76 & 0.59 & 0.59 & Montana (54) & 2.74 & 1.01 & 0.82 & 0.82 \\
\hline Virginia (131) & 2.73 & 0.80 & 0.61 & 0.61 & California (57) & 2.70 & 1.02 & 0.89 & 0.89 \\
\hline Wisconsin (71) & 2.17 & 0.68 & 0.56 & 0.56 & New Hampshire (10) & 1.97 & 0.99 & 0.95 & 0.95 \\
\hline Kentucky (120) & 2.45 & 0.79 & 0.62 & 0.62 & New Mexico (31) & 2.71 & 1.06 & 0.93 & 0.93 \\
\hline Illinois (102) & 2.26 & 0.79 & 0.65 & 0.65 & Colorado (61) & 3.57 & 1.21 & 1.01 & 1.01 \\
\hline Arkansas (75) & 2.23 & 0.75 & 0.63 & 0.63 & Idaho (42) & 3.04 & 1.18 & 0.99 & 0.99 \\
\hline Oklahoma (77) & 2.17 & 0.74 & 0.62 & 0.62 & Maine (16) & 1.95 & 1.00 & 0.93 & 0.93 \\
\hline West Virginia (55) & 2.21 & 0.77 & 0.65 & 0.65 & Alaska (19) & 3.55 & 1.24 & 1.03 & 1.03 \\
\hline Alabama (67) & 2.41 & 0.83 & 0.64 & 0.64 & Oregon (36) & 2.45 & 1.17 & 1.03 & 1.03 \\
\hline Mississippi (82) & 2.24 & 0.78 & 0.61 & 0.61 & Wyoming (23) & 2.75 & 1.25 & 1.10 & 1.10 \\
\hline Kansas (105) & 2.54 & 0.81 & 0.66 & 0.66 & New Jersey (21) & 2.72 & 1.21 & 1.12 & 1.12 \\
\hline Florida (66) & 2.55 & 0.80 & 0.65 & 0.65 & Maryland (24) & 2.83 & 1.16 & 1.08 & 1.08 \\
\hline Tennessee (95) & 2.16 & 0.80 & 0.68 & 0.68 & Utah (28) & 2.75 & 1.15 & 1.04 & 1.04 \\
\hline New York (62) & 2.03 & 0.82 & 0.70 & 0.70 & Delaware (3) & 2.09 & 1.25 & 1.25 & 1.25 \\
\hline South Dakota (64) & 2.63 & 0.84 & 0.68 & 0.68 & Connecticut (8) & 2.88 & 1.27 & 1.19 & 1.19 \\
\hline Nebraska (92) & 2.45 & 0.88 & 0.72 & 0.72 & Arizona (15) & 2.60 & 1.30 & 1.20 & 1.20 \\
\hline S. Carolina (46) & 2.15 & 0.78 & 0.68 & 0.68 & Washington (39) & 2.44 & 1.27 & 1.15 & 1.15 \\
\hline Indiana (92) & 2.27 & 0.83 & 0.71 & 0.71 & Massachusetts (14) & 2.48 & 1.43 & 1.39 & 1.39 \\
\hline Minnesota (87) & 2.29 & 0.84 & 0.72 & 0.72 & Nevada (16) & 3.25 & 1.55 & 1.41 & 1.41 \\
\hline Ohio $(88)$ & 2.09 & 0.86 & 0.74 & 0.74 & Rhode Island (5) & 2.17 & 1.65 & 1.66 & 1.66 \\
\hline Iowa (99) & 2.52 & 0.89 & 0.76 & 0.76 & Hawaii (4) & 3.67 & 3.17 & 3.15 & 3.15 \\
\hline
\end{tabular}

Note: Assume that banks can only expand within its home state and they care about risk minimization when adding each additional branch. 
TABLE 6. Effect of RN on the possibilities of GRD of small banks

\begin{tabular}{|c|c|c|c|c|c|}
\hline State (\# counties) & $\begin{array}{c}\text { TEMaxRR } \\
\% \Delta \mathrm{RR}\end{array}$ & $\begin{array}{c}\text { TEMinRisk } \\
\% \Delta \text { risk }\end{array}$ & State (\# counties) & $\begin{array}{c}\text { TEMaxRR } \\
\% \Delta \mathrm{RR}\end{array}$ & $\begin{array}{c}\text { TEMinRisk } \\
\% \Delta \text { risk }\end{array}$ \\
\hline Texas (248) & 5.8 & -6.7 & Pennsylvania (67) & 31.1 & -20.6 \\
\hline Missouri (115) & 16.9 & -13.1 & Vermont (14) & 12.7 & -8.8 \\
\hline Georgia (156) & 8.1 & -7.2 & North Dakota (51) & 21.0 & -17.7 \\
\hline N. Carolina (100) & 9.3 & -7.4 & Michigan (82) & 41.8 & -24.0 \\
\hline Louisiana (64) & 21.1 & -12.8 & Montana (54) & 29.1 & -24.5 \\
\hline Virginia (131) & 11.7 & -10.7 & California (57) & 8.1 & -9.2 \\
\hline Wisconsin (71) & 3.6 & -2.3 & New Hampshire (10) & 20.1 & -20.1 \\
\hline Kentucky (120) & 21.3 & -19.2 & New Mexico (31) & 49.1 & -29.0 \\
\hline Illinois (102) & 26.0 & -24.5 & Colorado (61) & 58.5 & -35.6 \\
\hline Arkansas (75) & 25.0 & -17.0 & Idaho (42) & 33.3 & -21.5 \\
\hline Oklahoma (77) & 21.6 & -16.7 & Maine (16) & 39.8 & -18.0 \\
\hline West Virginia (55) & 4.4 & -6.5 & Alaska (19) & 0.0 & 0.0 \\
\hline Alabama (67) & 11.6 & -13.9 & Oregon (36) & 40.1 & -25.4 \\
\hline Mississippi (82) & 14.8 & -10.1 & Wyoming (23) & 54.9 & -38.5 \\
\hline Kansas (105) & 10.6 & -11.6 & New Jersey (21) & 52.8 & -32.9 \\
\hline Florida (66) & 10.7 & -12.2 & Maryland (24) & 75.7 & -39.5 \\
\hline Tennessee (95) & 31.9 & -25.5 & Utah (28) & 47.6 & -26.0 \\
\hline New York (62) & 12.7 & -13.2 & Delaware (3) & 58.8 & -40.8 \\
\hline South Dakota (64) & 10.0 & -9.1 & Connecticut (8) & 41.5 & -29.1 \\
\hline Nebraska (92) & 27.8 & -22.8 & Arizona (15) & 45.8 & -34.9 \\
\hline S. Carolina (46) & 16.9 & -14.4 & Washington (39) & 22.3 & -17.9 \\
\hline Indiana $(92)$ & 22.9 & -17.6 & Massachusetts (14) & 81.3 & -46.8 \\
\hline Minnesota (87) & 34.8 & -24.7 & Nevada (16) & 80.3 & -39.7 \\
\hline Ohio (88) & 22.4 & -16.8 & Rhode Island (5) & 34.9 & -32.2 \\
\hline Iowa (99) & 41.5 & -28.2 & Hawaii (4) & 0.0 & 0.0 \\
\hline
\end{tabular}

This table reports median (across counties) percentage changes in return-to-risk ratio and risk in the

Thought Experiment for banks with 5 branches before and after the RN act.

1. "TEMaxRR": Thought experiment when a bank sequentially add branches to maximize return-to-risk ratio.

2. "TEMinRisk": Thought experiment when a bank sequentially add branches to minimize risk.

3. $\% \Delta R R=($ post_RR - pre_RR $) / p r e_{-} R R * 100$. This percentage change is calculated for each county.

The reported number is the median value of counties for each state.

4. $\% \Delta R i s k=($ post_Risk - pre_Risk $) / p r e_{-}$Risk $* 100$. This percentage change is calculated for each county.

The reported number is the median value of counties for each state. 
Table 7: Estimation of Bank Preferences

\begin{tabular}{|c|c|c|}
\hline Parameter & Estimate & (s.e.) \\
\hline$\sigma_{\varepsilon}($ in million $\$)$ & 5.63 & $(4.02)$ \\
\hline $\begin{array}{r}\text { Cost of Insolvency Parameter } \bar{\rho} \\
\text { (in percentage points of tax per percentage point of prob. insolvency) }\end{array}$ & $10.44^{* * *}$ & $(1.92)$ \\
\hline \multicolumn{3}{|l|}{ Branch network diseconomies of scale: } \\
\hline Number of branches (in million $\$$ per branch) & $-2.43^{* *}$ & $(0.86)$ \\
\hline Number of branches square (in million $\$$ per branch sq.) & $-0.11^{*}$ & $(0.05)$ \\
\hline \multicolumn{3}{|l|}{ Branch network economies of density: } \\
\hline $\begin{array}{l}\text { Average distance to county HQs } \\
\text { (in million } \$ \text { per } 100 \text { miles and per branch) }\end{array}$ & $-0.178^{* *}$ & $(0.048)$ \\
\hline Average distance to county HQs square & 0.005 & $(0.004)$ \\
\hline \multicolumn{3}{|l|}{ Branch network adjustment costs. Denovo branching } \\
\hline Denovo Branch Creation within state (in million $\$$ per branch) & $-1.520^{* *}$ & $(0.259)$ \\
\hline Denovo Branch Creation out state (in million $\$$ per branch) & $-3.255^{* *}$ & $(0.408)$ \\
\hline \multicolumn{3}{|l|}{ Branch network adjustment costs. Merger } \\
\hline Merger within state (in million $\$$ per new branch) & $-1.494^{* *}$ & $(0.519)$ \\
\hline Merger out state (in million $\$$ per new branch) & $-2.193^{* *}$ & $(0.495)$ \\
\hline Merger within state $\times$ small bank dummy (in million $\$$ per new branch) & $-2.758^{*}$ & $(1.110)$ \\
\hline Merger out state $\times$ small bank dummy (in million $\$$ per new branch) & $-4.090^{* *}$ & $(0.698$ \\
\hline
\end{tabular}


Figure 1

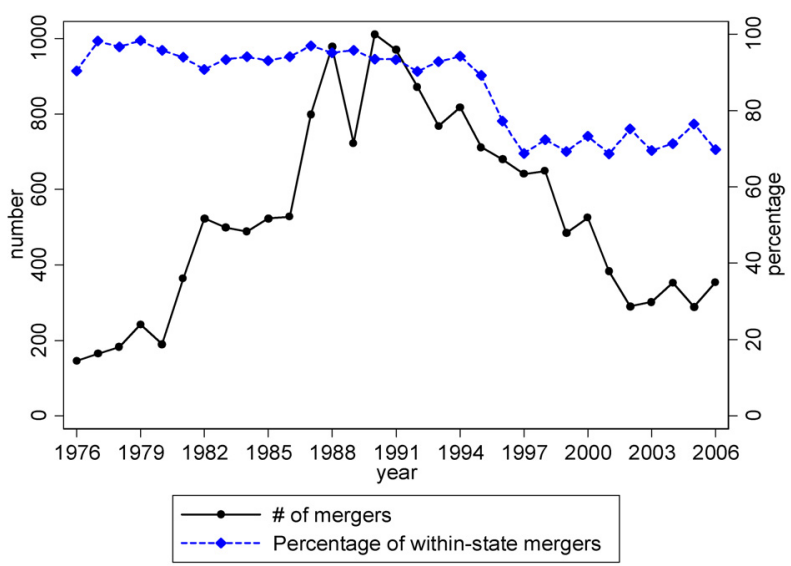

Figure 2A

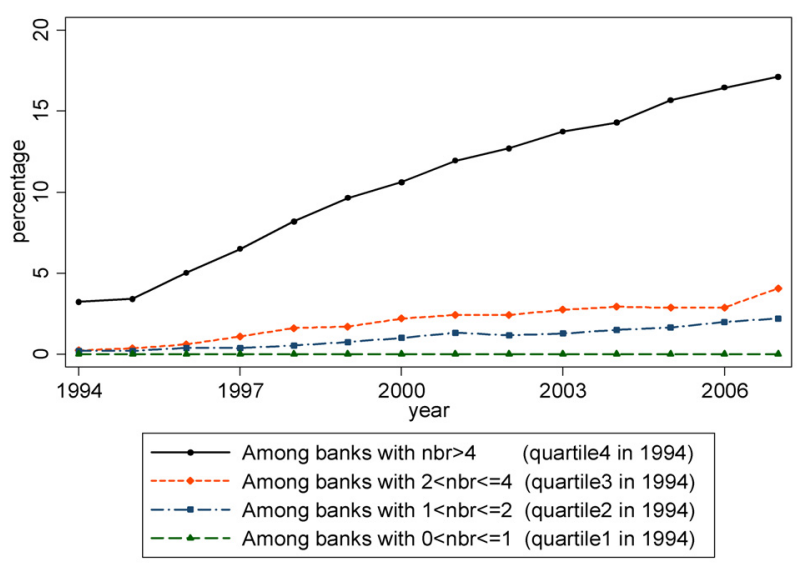

(a) By bank size as measured by number of branches

Figure 2B

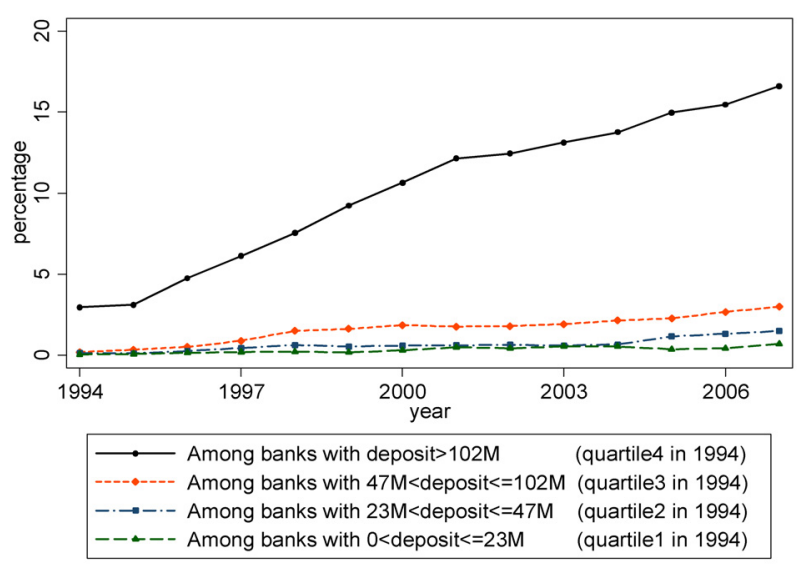

(b) By bank size as measured by volume of deposits 
Figure 3: Cross-Sectional Distributions of the Logarithm of Deposits per Branch CROSS-SECTIONAL DISTRIBUTION OF LOG(DEPOSITS PER BRANCH) CROSS-SECTIONAL DISTRIBUTION OF LOG(DEPOSITS PER BRANCH
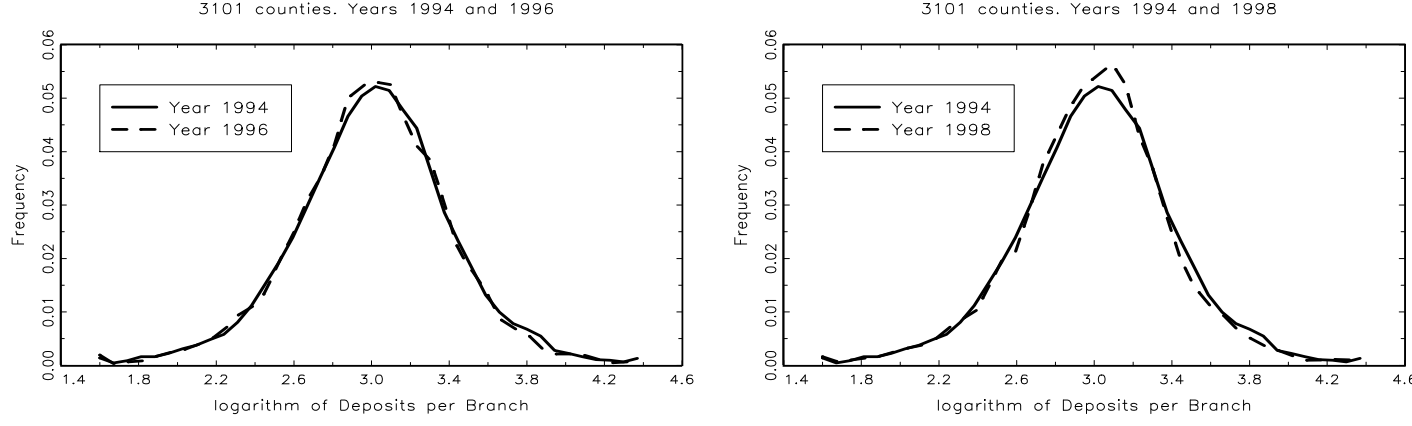

CROSS-SECTIONAL DISTRIBUTION OF LOG(DEPOSITS PER BRANCH)

CROSS-SECTIONAL DISTRIBUTION OF LOG(DEPOSITS PER BRANCH)

3101 counties. Years 1994 and 2002
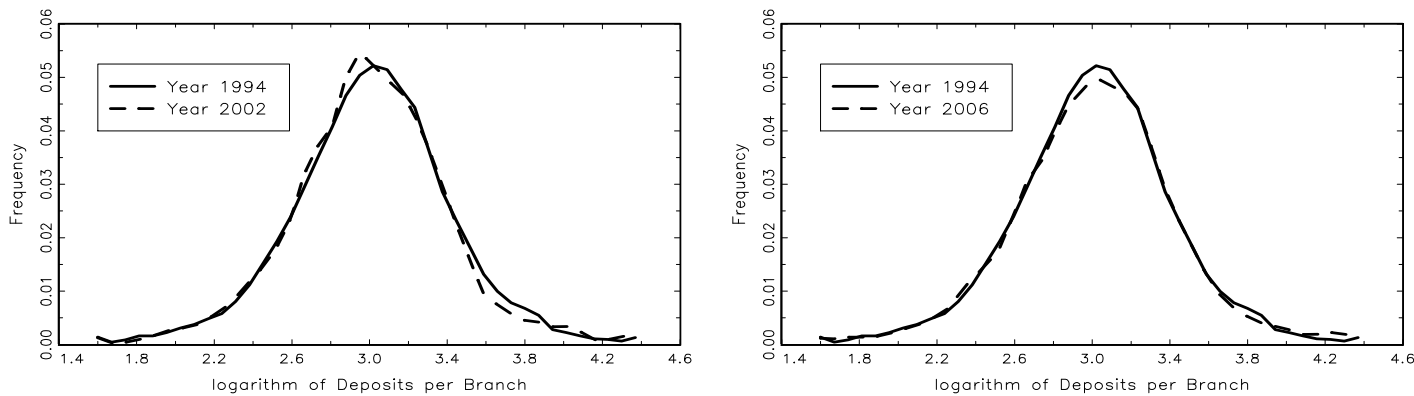

Figure 4: Cross-Sectional Distributions of Estimated Expected Returns
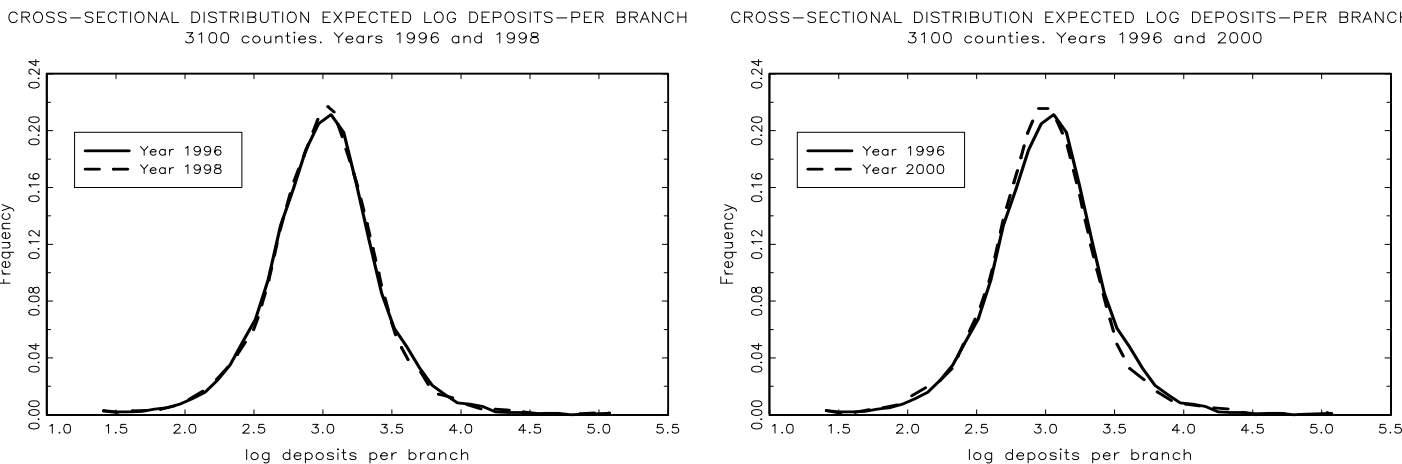

CROSS-SECTIONAL DISTRIBUTION EXPECTED LOG DEPOSITS-PER BRANCH CROSS-SECTIONAL DISTRIBUTION EXPECTED LOG DEPOSITS-PER BRANCH
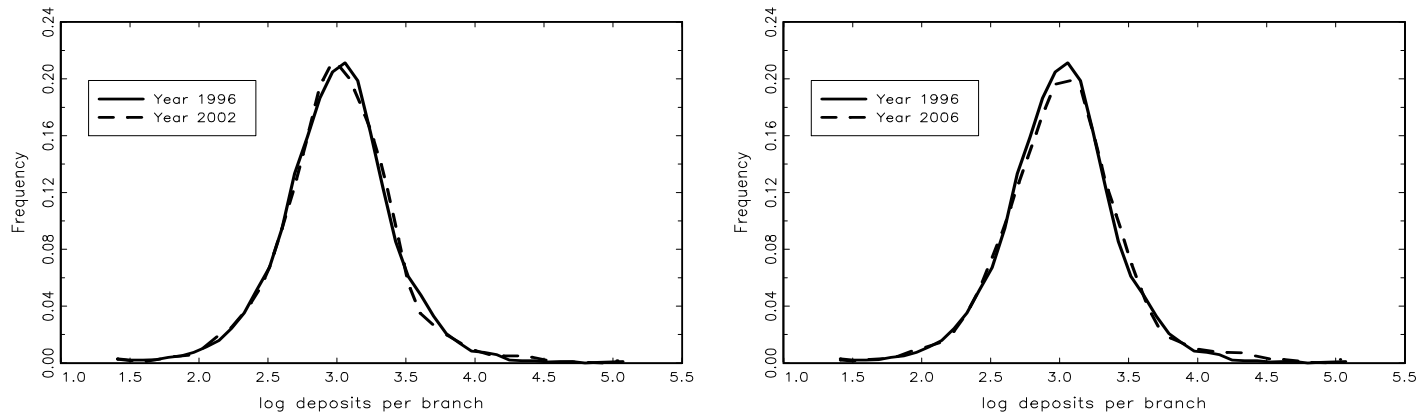
Figure 5: Cross-Sectional Distributions of Diversifiable Risk
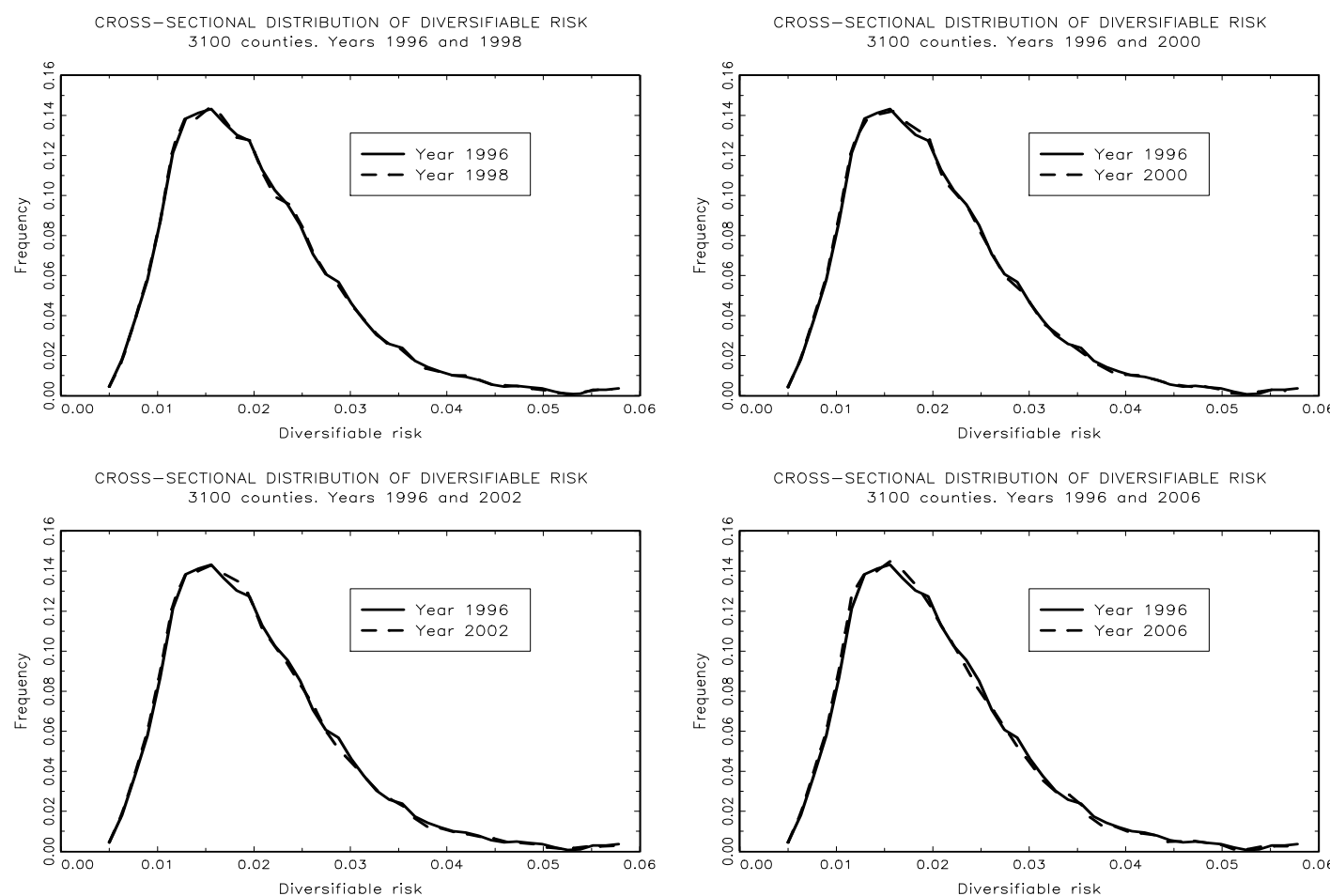

Figure 6: Cross-Sectional Distributions of Systematic Risk

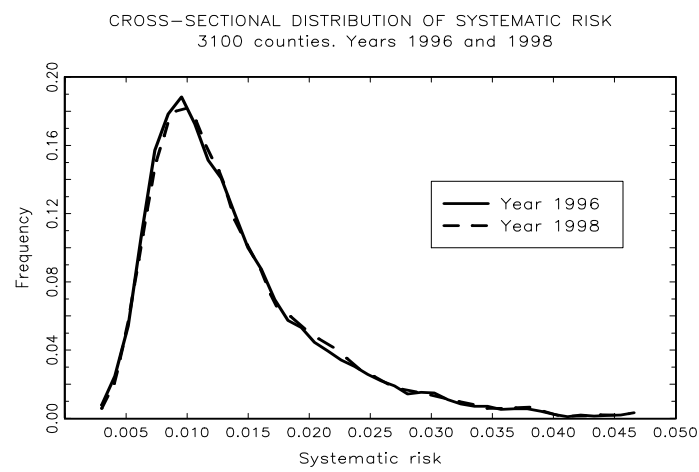

CROSS-SECTIONAL DISTRIBUTION OF SYSTEMATIC RISK

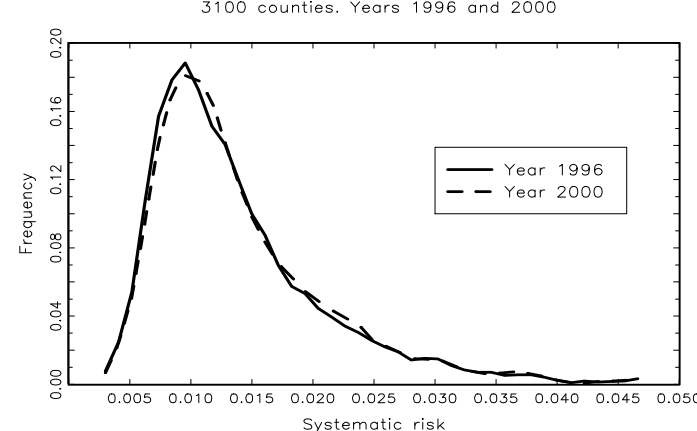

CROSS-SECTIONAL DISTRIBUTION OF SYSTEMATIC RISK
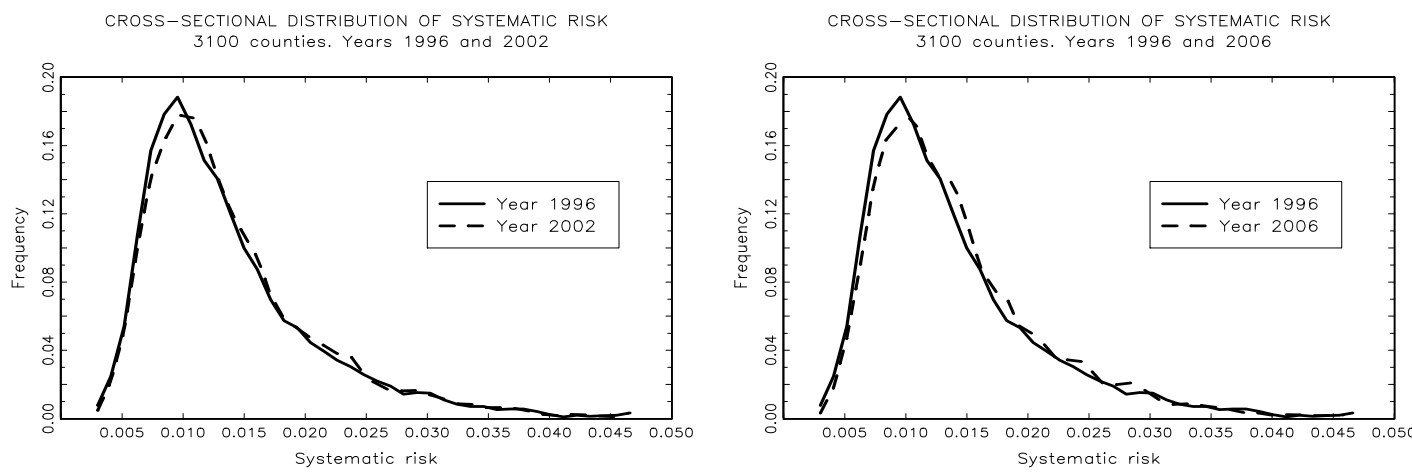
Figure 7: Efficient Frontiers in 1995
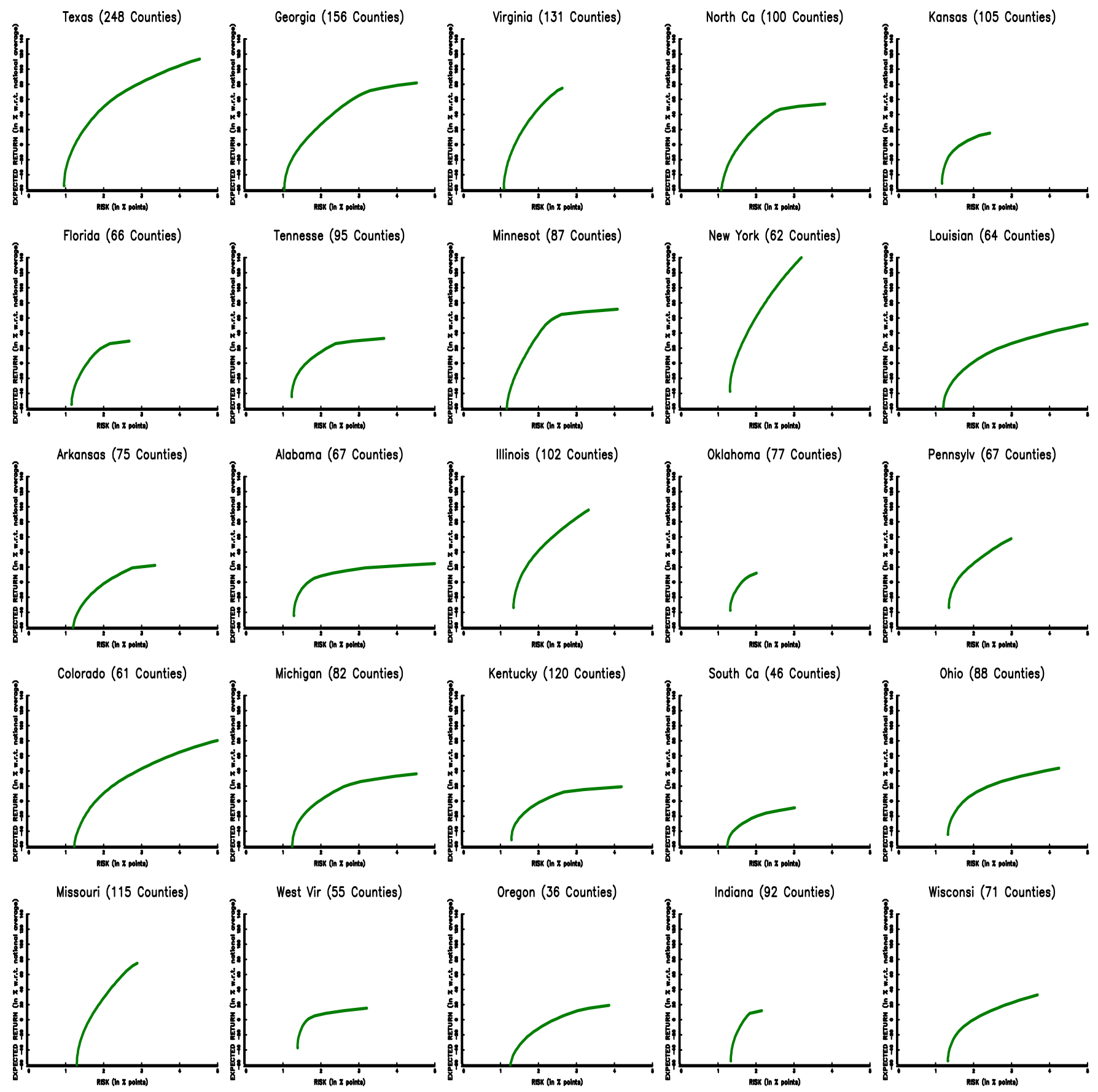
Figure 7: Efficient Frontiers in 1995 (Continued)
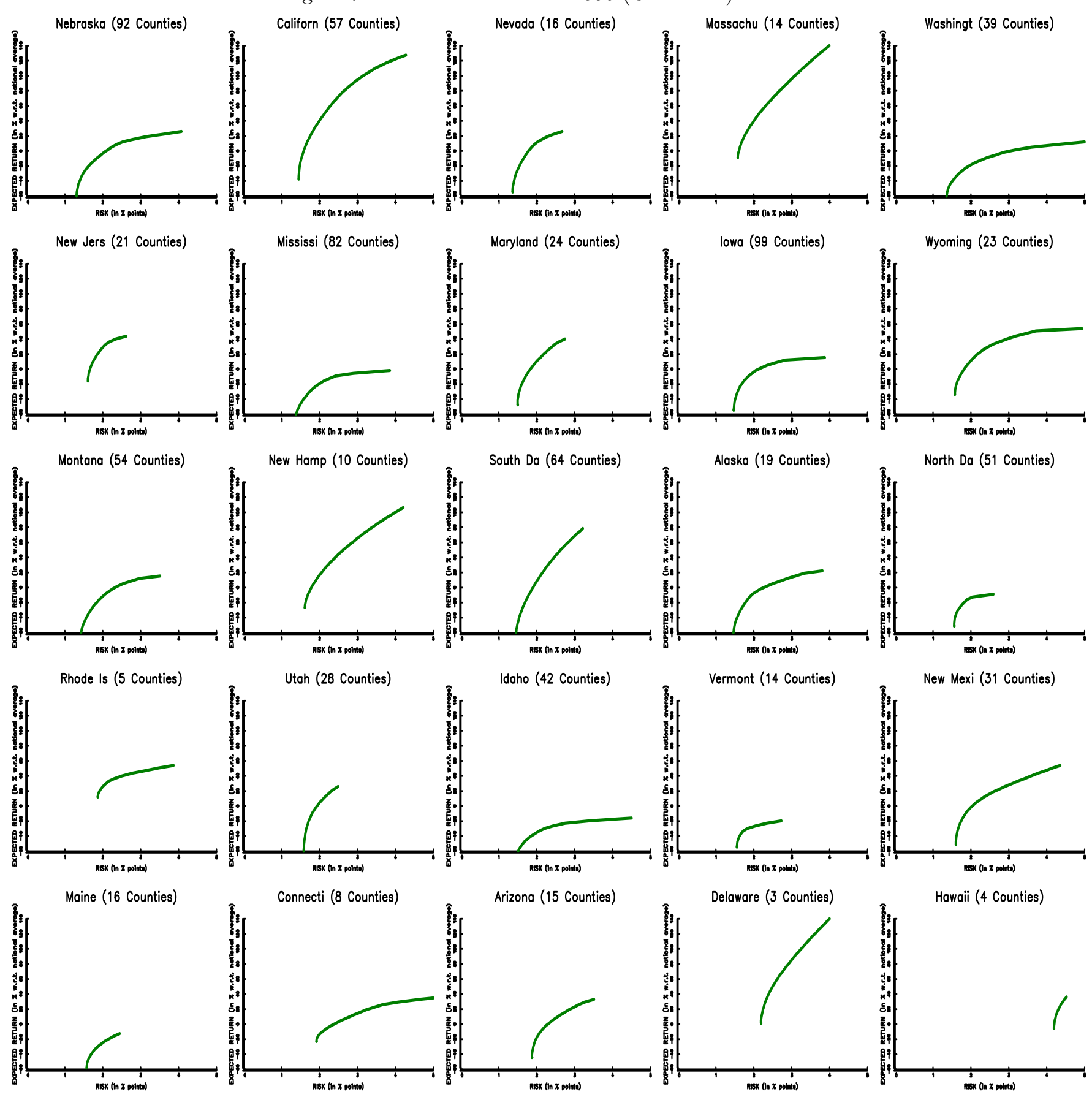


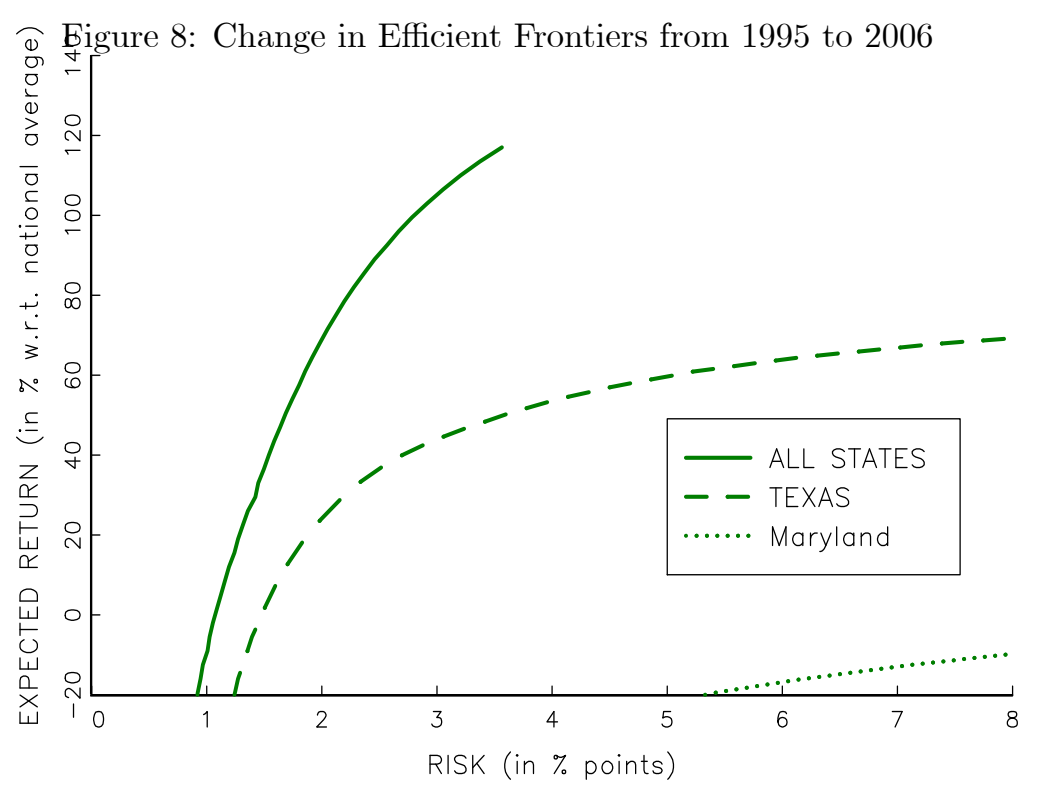

Figure 9A: Distribution of Banks' Expected log-deposits-per-branch in 1995

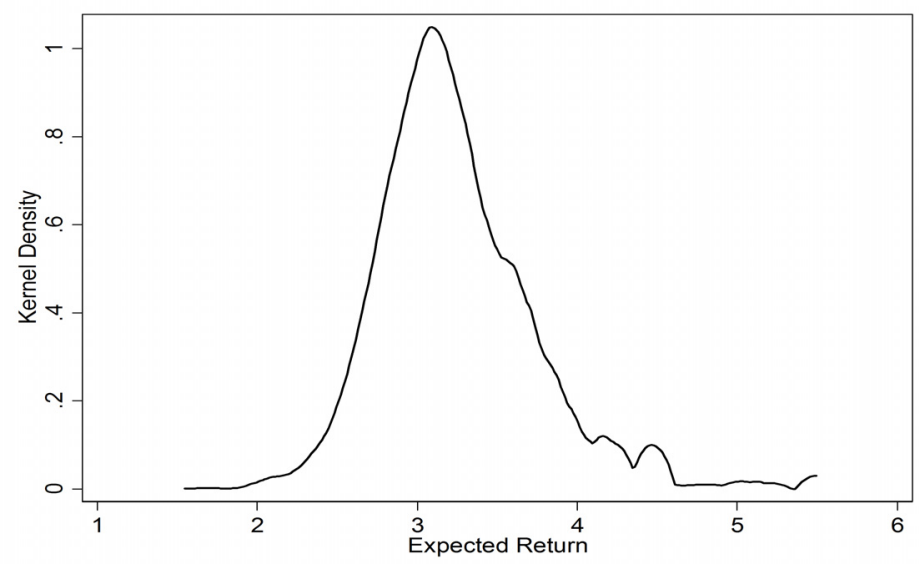

Figure 9B: Distribution of Banks' Risk of deposits in 1995

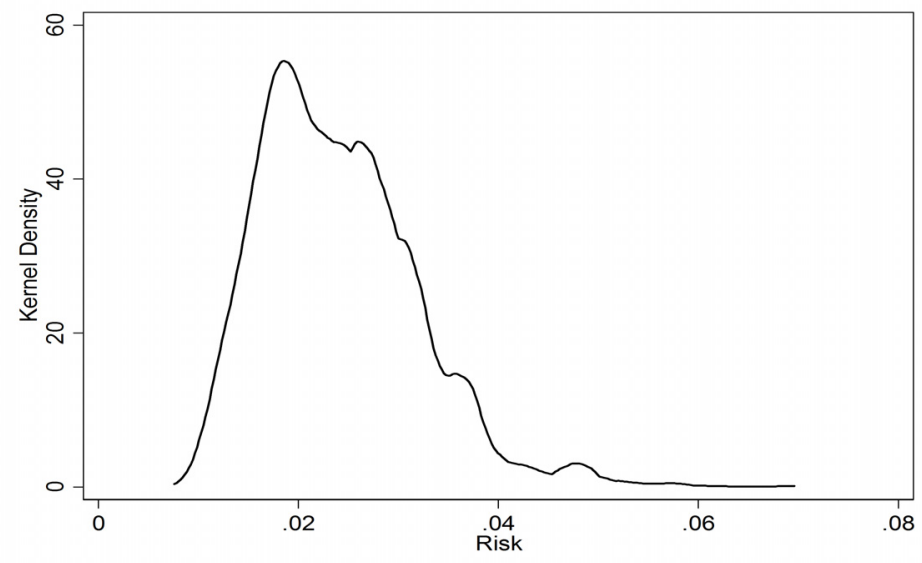


Figure 10A: Distributions of Banks' Expected log-deposits-per-branch in 1995 and 2006

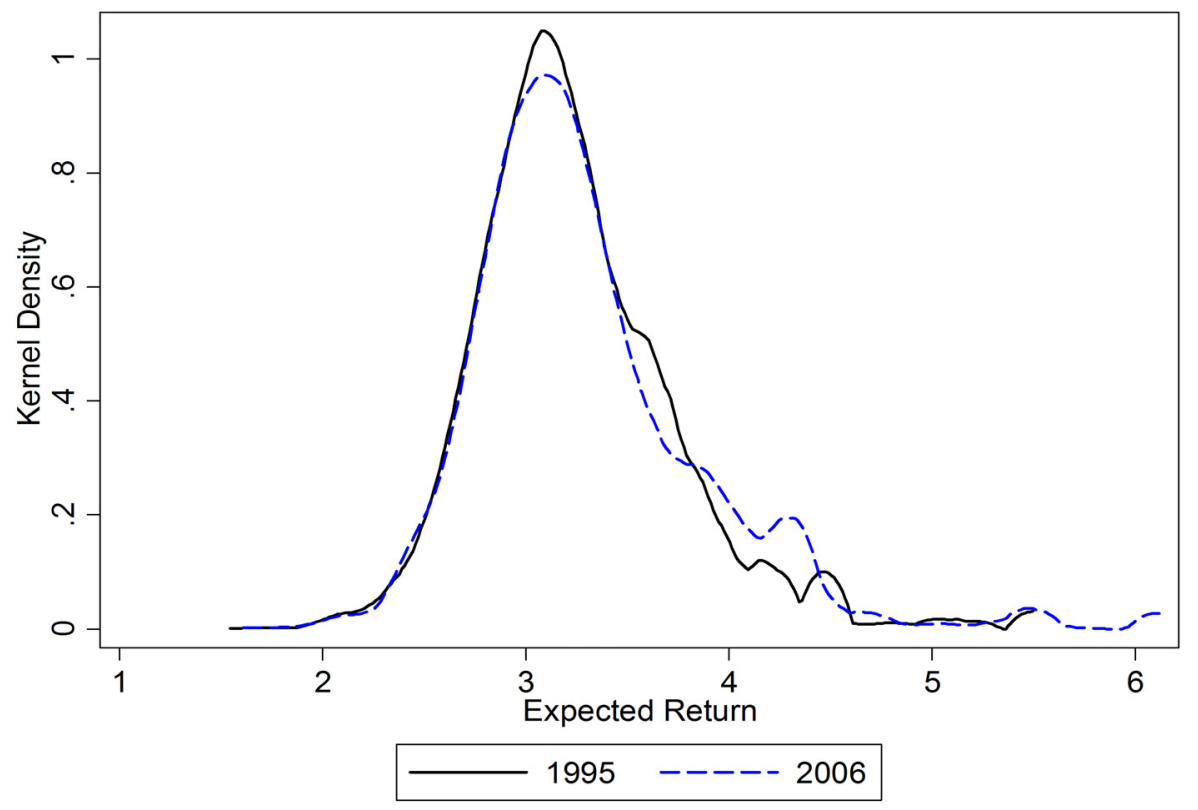

Figure 10B: Distributions of Banks' Risk of deposits in 1995 and 2006

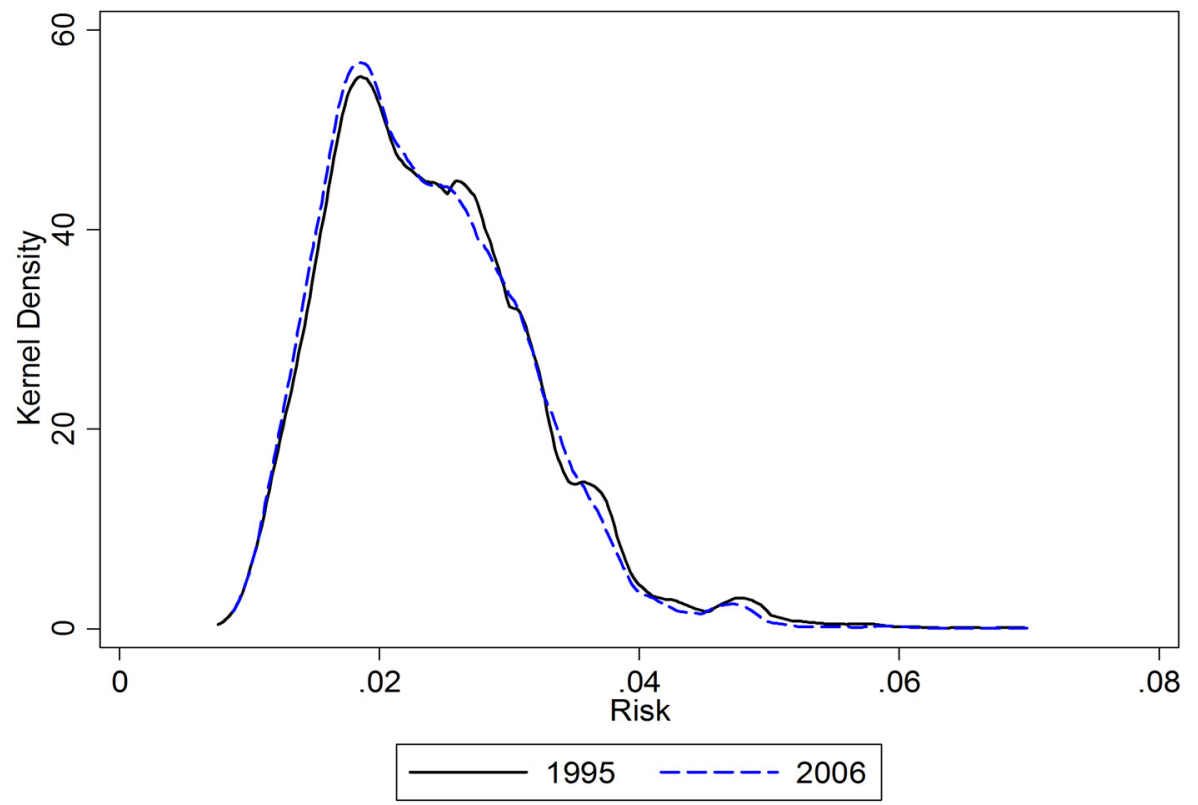


Figure 11: Decomposition of change in distribution of banks' risk: 1995-2006
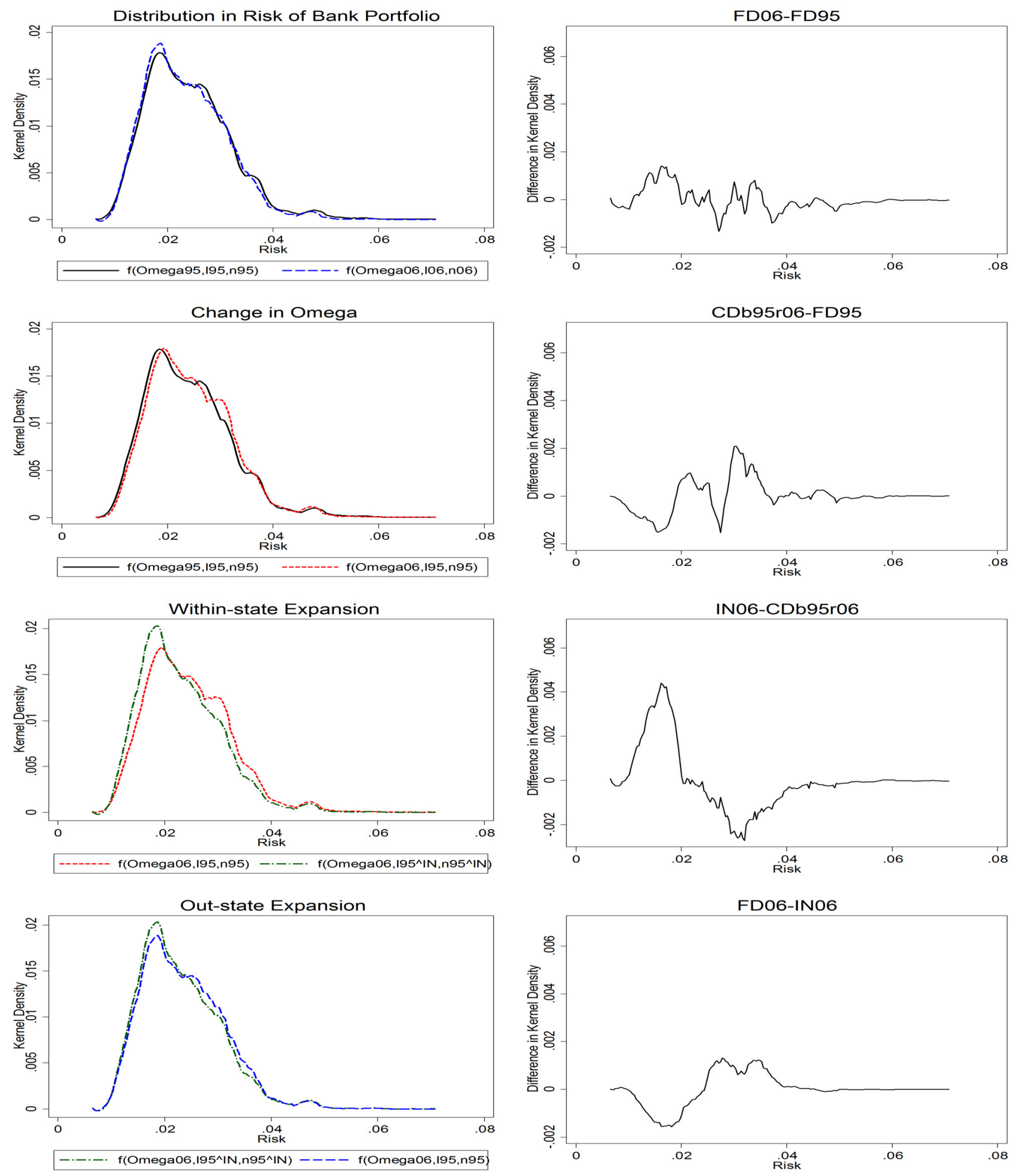
Figure 12: Decomposition of change in distribution of banks' expected deposits-per-branch: 1995-2006
